\title{
EL MODELO DE UTILIDAD
}

Jorge Halperin Grobman

\section{Introducción}

La octava Ronda de Negociaciones Comerciales Multilaterales del Acuerdo General sobre Tarifas y Comercio - conocido como el GATT - presentó en Uruguay un cambio radical frente a las rondas previas. Con anterioridad a ésta, las negociaciones se desarrollaron dentro del marco de un comercio internacional que giraba en torno al liderazgo norteamericano de la posguerra, en el que el objetivo principal había sido la expansion del comercio internacional de manufacturas y la reducción de barreras arancelarias.

El impacto de la revolución tecnológica y sus consecuencias en el proceso productivo, cambiaron el panorama. Los países industrializados se vieron precisados a intentar la adaptación del comercio internacional a las nuevas circunstancias de la economía mundial. La ineficacia de muchas estructuras legales e institucionales y las diferentes posturas políticas de los países en lo que a protección de tecnología concierne, generaron nuevas iniciativas e intentos de imposición de reglas en lo concerniente a la multilateral administración de la economía mundial.

En los últimos años, los países en vías de desarrollo, por tener una percepción de la propiedad industrial que priorizaba aspectos de política económica sobre consideraciones legales, crearon serios problemas en las economías de los países industrializados ${ }^{1}$. En el caso del Grupo Andino, el sistema de patentes favoreció más el aspecto económico que el moral al pre-

1 Se sostiene que la venta mundial de productos pirateados (comercializados sin licencias) en los que se utiliza propiedad intelectual sin autorización ascienden a 60 billones de dólares por año. Esto se traduce en pérdidas de 25 millones de dólares 
valecer el interés público sobre el privado. En aquel contexto era entendible la exclusión de algunos sectores en la protección y una menor duración de los derechos.

La inclusión de nuevos temas en la agenda de debates se convirtió en un imperativo para los países industrializados. De ellos uno muy importante fue el relativo a la protección de derechos de propiedad intelectual, que claramente iba más allá de la tradicional jurisdicción. Un código de conducta inspirado en los lineamiento del GATT permitiría aplicar sanciones económicas a quienes no siguieran la nueva corriente impuesta. Éste es el contexto dentro del cual se producen los cambios en el derecho de patentes en la subregión.

La Decisión 313, publicada en la Gaceta Oficial del Acuerdo de Cartagena el 14 de febrero de 1992, legisla el Régimen Común sobre Propiedad Industrial. Ella sustituye a la Decisión 311, que a su vez había reemplazado a la Decisión 85. En el ámbito de la legislación nacional, el decreto ley 26017 , publicado el 28 de diciembre de 1992 bajo el título de «Ley general de propiedad industrial», reúne a manera de código las distintas instituciones del derecho industrial. La exposición de motivos precisa que la nueva ley modifica totalmente el régimen del decreto supremo 001 71, reglamento de la antigua ley de industrias, y además, de acuerdo a lo dispuesto en el artículo 118 de la Decisión 313, amplía y modifica el régimen de protección establecido en dicha norma.

para compañías en Estados Unidos y representa aproximadamente un 15\% del déficit comercial norteamericano. Ver Intellectual Property Rights, Global Consensus, Global Conflict? Gadbaw and Richards Ed. Vestview Press, 1988.

En lo que concierne a productos farmacéuticos —uno de los puntos de mayor controversia- el presidente de la Asociación de compañías manufactureras de los Estados Unidos mencionó que la ausencia de patentes para productos farmacéuticos en Argentina permite a laboratorios en aquel país copiar productos norteamericanos sin incurrir en costos de investigación y desarrollo. La Asociación sostiene que esta falta de protección sólo en Argentina significó un costo para la industria farmacéutica norteamericana de U.S. $\$ 83$ millones en 1987 y por lo menos U.S. $\$ 526$ millones desde 1980. Ver: The Intellectual Property Committee. Keindaren and Unice (June 1988), Basic Eramework of GATT Provisions on Intellectual Property. Statements of views of the European. Japanese and United States business communities. 
Una de las incorporaciones importantes en ambos cuerpos legales la constituye el régimen de modelos de utilidad. Normas sobre éste se encuentran en el capítulo II de la Decisión y en el título V del decreto ley, bajo el título -en ambos casos- «De los modelos de utilidad». Este artículo tiene por objeto analizar los alcances del nuevo régimen. Para ello, se divide el estudio en tres partes: nociones de carácter general, régimen anterior, y análisis de la actual normativa.

La primera parte describirá las características de la institución. Se abordarán los puntos más característicos que se consagran en la doctrina y legislación comparadas. Importante es referirse a los antecedentes históricos, puesto que las razones que motivaron la introducción primera de la figura permiten entender los alcances que ella tiene. Es importante también hacer comparaciones con la patente de invención y el modelo industrial, puesto que se trata de figuras de la propiedad industrial con las que el modelo de utilidad tiene vínculos, además de que conceptualizando las diferencias se permite un mejor entendimiento del régimen. Como parte final, se examinará el método australiano de protección de invenciones menores, conocido como «Petty patent». Un estudio acerca de los modelos de utilidad debe forzosamente contemplarlo, por marcar éste una evolución importante en el sistema.

La segunda y tercera parte tratarán del recientemente derogado régimen de modelos de utilidad y del actualmente vigente, respectivamente. El decreto supremo 084-84-ITI/IND y la Decisión 85, «Reglamento para la aplicación de las normas sobre propiedad industrial», puesto en vigencia mediante el decreto ley 22532 , corresponde a la normativa derogada. Entendiendo sus deficiencias el lector justificará la derogatoria, así como también comprenderá mejor la sistemática y alcances del nuevo modelo de utilidad.

Excede a los fines de este artículo evaluar las consideraciones políticas y económicas subyacentes en la radical reforma ocurrida en el derecho de patentes nacional ${ }^{2}$. La Decisión, confrontada con su antecesora, es menos controvertida frente a la legislación comparada, y la ley en muchos as-

2 Acerca de la Decisión 313 se recomienda leer KRESALJA, Baldo, «La Decisión 313» en: Thémis, 23, PUC, Lima 1992. 
pectos supera a aquélla en la intención de hacer prevalecer los intereses del inventor ${ }^{3}$. Es oportuno comentar que, si bien enfrentamos cambios importantes, no hay razón para sostener que son estructurales, pues significaría negar que hasta ahora la oscilación pendular ha sido característica de nuestras políticas económicas, y lo que hoy se implanta como nuevo no es más que -en muchos casos- repetición del régimen precedente al derogado. En esta línea de pensamiento, se hace necesario extraer conclusiones, para lo cual es forzoso evaluar los efectos que produjo el anterior marco jurídico de la inventiva, instaurado con la Decisión 85 , hoy sustituida por la Decision 313.

Es cierto que en países en desarrollo el derecho de patentes siempre ha generado controversias, pero las dudas respecto a su conveniencia no son «invención» nuestra. Provienen, en parte, de la autocrítica que se desató en algunos países europeos durante el siglo pasado y que llevó, en algunos casos, a la abolición de leyes. Interesa destacar que cuando fue promulgada la ley de privilegios, el 28 de enero de 1869 , considerada la primera ley de papatentes nacional, en esos países europeos se estaba cuestionando el sistema de patentes y su abolición se hacía realidad en algunos de ellos ${ }^{4}$.

En lo que el modelo de utilidad se refiere, las características del mismo lo constituyen en una figura que difícilmente encontrará detractores. Las únicas discusiones posibles se refieren a las características o rasgos particulares del sistema, los mismos que serán abordados a lo largo del artículo. La constante remisión al derecho de patentes es obligada en un artículo sobre modelos de utilidad. Para un mejor entendimiento es necesario tener

3 Por citar un ejemplo, la Decisión permite la concesión de patentes para productos farmacéuticos. Sin embargo, la tercera disposición transitoria faculta a los países miembros a extender hasta un máximo de diez años (febrero del año 2002) la excepción de patentabilidad para los mismos. La ley en la disposición final cuarta permite la patentabilidad a partir de 1994.

4 PATEL J. Surendra, «The Patent System and the Third World", en World Development, 1974, vol. 2, $\mathrm{N}^{\circ} 9$, pp. 4-5.

En Holanda la ley de patentes fue abolida en 1869 y luego reimplantada en 1912. En Suiza, bajo el mandato constitucional, el Gobierno federal no podía establecer un régimen de patentes directamente. El referéndum era necesario, y su convocatoria no fue aprobada en varias oportunidades. Cuando se autorizó su convocatoria, en dos ocasiones resultó improductivo. Sólo en 1887 la propuesta fue aceptada. 
claras las nociones básicas del régimen general de patentes de invención. En este orden de ideas, se sugiere el previo estudio de éste ${ }^{5}$.

\section{Primera parte \\ Nociones de carácter general}

\subsection{Concepto}

Un análisis de cuerpos legales y de posturas doctrinarias permite establecer los siguientes rasgos como propios del modelo de utilidad ${ }^{6}$ :

1. Opera siempre en objetos de uso y dominio público, es decir, sobre herramientas, instrumentos de trabajo, aparatos dispositivos, etc.

2. Siendo una creación de forma, él debe proyectarse y materializarse en el espacio.

3. El objeto conocido, poseedor de la nueva forma espacial, se destina a un nuevo uso práctico que facilita la acción del hombre.

5 En nuestro idioma, se pueden consultar entre otras las siguientes obras:

ASCARELLI, Tulio, Teoría de la concurrencia y de los bienes inmateriales. Barcelona, Bosch Casa Editorial, 1976.

BAYLOS CORROSA, Hemenegildo, Tratado de propiedad industrial, Madrid, Editorial Civitas S.A., 1978.

BREUER MORENO, P.C., Tratado de patentes de invención, 2 tomos, Buenos Aires, Abeledo Perrot, 1957.

DI GUGLIELMO, Pascual, La invención patentable, Buenos Aires: Victor P. de Zavalía, 1968.

Sobre modelos de utilidad puede consultarse:

POLI, Iván Alfredo, El modelo de utilidad, Buenos Aires, Ediciones Depalma, 1982.

HALPERIN, Jorge, El modelo de utilidad. Tesis para optar el grado de bachiller en la Facultad de Derecho de la Pontificia Universidad Católica del Perú, Lima, 1987.

HALPERIN Jorge, «El modelo de utilidad», en Informativo Legal Rodrigo, enero 1988 .

6 La Organización Mundial de la Propiedad Intelectual tiene registrados más de 30 países que cuentan con un sistema para la protección de invenciones alternativo al de las patentes. Este sistema se ha extendido principalmente bajo los principios del modelo de utilidad. 


\subsubsection{Ejemplo}

Imaginemos un objeto común: el sacacorchos en espiral ${ }^{7}$. Por más trivial que sea el artículo, brinda una prestación significativa, además de haber presentado originalidad frente a todo lo existente en el momento de su introducción. Tales circunstancias determinaron que el nuevo producto recibiese el calificativo de invento. Posteriormente, a este sacacorchos se le adiciona una palanca que facilita la extracción del corcho y brinda mayor seguridad. Dicha palanca mejora significativamente el uso del objeto que la contiene. El sistema de palanca, en este caso, es un principio mecánico que ha sido trasladado de un aparato ya conocido a otro igualmente conocido. Ha producido en este último un cambio de forma que mejora su empleo.

\subsection{Importancia}

Razones distintas esgrimen los defensores de la institución. Tanto países desarrollados como en desarrollo cuentan con el sistema de modelos de utilidad. Al tradicional argumento sustentado en el desarrollo de una tecnología nacional —razón ésta considerada por los países en desarrollo-, se suma otra más moderna y que ha tenido nacimiento en los países tecnológicamente avanzados: la necesidad de contar con una alternativa de protección más fácil de obtener en términos de tiempo y dinero ${ }^{8}$.

Dado el escaso avance científico y tecnológico existente en los países en vías de desarrollo, las invenciones con más opciones de surgir no serán precisamente de «primer grado», es decir, no identificarán productos totalmente nuevos. Es de esperar que mayormente se gesten invenciones que, basadas en productos ya existentes, los mejoren para otros usos o para que

7 Ejemplo extraído de: LACRUZ, José Luis, «El modelo de utilidad y sus diferencias con la patente de invención». En: Revista de Derecho Español y Americano. Madrid: Año XIII, II época (abril - junio 1968), p. 114.

8 El caso de Australia, al que más adelante nos referiremos (ver infra 1.5), es claro ejemplo de la nueva corriente que se está gestando en los países desarrollados. El sentido que para estos países tiene la introducción de la figura, u otra similar, no es sino el de abrirles a los pequeños inventores la posibilidad de un camino más rentable en términos de tarifa y de rápido acceso, aunque con un beneficio de exclusividad menor. 
funcionen mejor en las condiciones locales ${ }^{9}$. La necesaria adquisicion de tecnología básica, como primer paso hacia el progreso tecnológico, es reconocida en diversos estudios ${ }^{10}$. Esta tecnología básica corresponde a los perfeccionamientos de los procesos o maquinarias existentes, que encuentran en el modelo de utilidad la alternativa de protección.

La utilización del modelo es hecha mayormente por inventores nacionales. Estadísticas de propiedad industrial reflejan que el número de solicitudes de registro de modelos de utilidad es equivalente al de solicitudes de patentes, y que en todos los países que prevén la protección, la gran mayoría de las solicitudes son presentadas por nacionales o residentes en el país. Esto se aplica incluso en los países en que el porcentaje de solicitudes de extranjeros es más elevado. Por ejemplo, en España, el $80 \%$ aproximadamente de todas las solicitudes de patentes es presentado por extranjeros, mientras que ese porcentaje alcanza sólo alrededor del $10 \%$ cuando se trata de solicitudes de modelos de utilidad" ${ }^{\prime}$.

En conclusión, podría decirse que un país en vías de desarrollo, teniendo un régimen de modelos de utilidad, debería percibir un constante depósito de aplicaciones mayoritariamente de propiedad de nacionales. Dado que en estos países las invenciones patentables son presentadas casi exclusivamente por extranjeros ${ }^{12}$, las oficinas de patentes debieran concentrarse

9 LEIVA, Jorge, «Evaluación de las implicancias técnico-económicas del proyecto: Ley sobre invenciones, dibujos y modelos industriales y examen de contratos, presentado por la OMPI a los gobiernos de Centroamérica y Panamá». En: Revista de Derecho Industrial. Buenos Aires, Año $5 \mathrm{~N}^{\circ} 15$ (setiembre-diciembre 1983), p. 539.

10 SHOJI, Matsui, «The transfer of technology to developing Countries: Some proposals to solve current problems». En: A.I.P.P.I., Quarterly journal of the Internacional Association for the Protection of the Industrial Property. Vol. 2, $\mathrm{N}^{\circ} 2$ (1977), p. 4.

1 NACIONES UNIDAS, «La función del sistema de patentes en la transmisión de tecnología a los países en desarrollo». Documento $N^{\circ}$ TD/A 11/19, REV. 1 NUEVA YORK NACIONES UNIDAS, 1975.

12 A fínales de la década del 70 , de 35 millones de patentes sólo el $6 \%$ había sido expedido en países en vías de desarrollo. De este $6 \%$, los $5 / 6$ eran propiedad de extranjeros (esto determina que las patentes «made in país subdesarrollado» llegasen sólo al $1 \%$ del total), y entre el 90 y $95 \%$ de las patentes registradas en los países subdesarrollados quedaban sin ser trabajadas. Ver: SHOJI, Matsui. Ob. cit., p. 6. 
-en lo que a solicitudes nacionales concierne- en el modelo de utilidad. Como resultado, se iría adquiriendo el dominio de una tecnología básica nacional que paulatinamente podría acortar la brecha tecnológica con países desarrollados.

\subsubsection{Antecedentes históricos}

Alemania y Japón fueron los primeros países en adoptar el régimen de modelos de utilidad. Las razones esgrimidas difieren sustancialmente y su conocimiento contribuye a entender mejor la institución.

Las leyes de patentes alemanas de 1877 y 1891 establecían un concepto de progreso técnico o altura inventiva muy estricto. Así entonces, una serie de invenciones no accedían a la patentabilidad, debido a que no alcanzaban el nivel técnico necesario. Herramientas, implementos y objetos de uso práctico quedaban sin protección alguna. Paralelamente, en otros países europeos la óptica más liberal del progreso técnico permitía que esos mismos artículos sí obtuvieran patente ${ }^{13}$. De manera adicional, el sistema de concesión de patentes establecía complicados trámites para la obtención del registro, además de las considerables demoras, producto de un sistema de examen previo. Esto originaba adicionalmente el incremento de los costos de procedimiento ${ }^{14}$.

Como bien se ha apuntado, no es de sorprender que el nacimiento de la figura se diera en Alemania ${ }^{15}$. Francia, bajo el imperio de la ley del 5 de julio de 1844 , no exigía ningún nivel mínimo de patentabilidad para la concesión de derechos sobre invenciones. Inglaterra, por su parte, a medio camino entre el liberalismo francés y la rigurosidad alemana, alentaba un sistema benigno para la concesión de patentes ${ }^{16}$.

${ }^{13}$ LADAS, Stephen P., Patents, trademarks ande related rights, national and international protection. Cambridge Mass.: Harvard University Press, 1975, t.II, p. 949.

14 LACRUZ, ob. cit., p. 116.

${ }^{15}$ DÍAZ VELASCO, «Los modelos de utilidad y la protección de las invenciones menores». En: Revista de la Propiedad Industrial. Año II ( $2^{\circ}$ trimestre 1955), p. 170 .

${ }^{16}$ El sistema inglés de concesión de patentes exigía el «inventive step», esto es, que la invención representase un avance en el progreso técnico industrial. Este 
Finalmente, la necesidad de crear una nueva institución se hizo apremiante al descartarse la posible cobertura de estas creaciones por la ley de diseños industriales ${ }^{17}$. De este modo, el nuevo derecho de propiedad industrial cerró la brecha existente entre las leyes de patentes y modelos industriales. Se hizo posible la protección de creaciones que, reivindicando nuevas formas, expresaban también adelantos técnicos.

En 1905, Japón promulgó la ley de modelos de utilidad. Lejos de surgir como reacción a una ley de patentes con un riguroso sistema de concesión y altura inventiva significativa, el modelo de utilidad japonés respondió a los lineamientos de una política tecnologica muy bien estructurada ${ }^{18}$. Se trató de la utilización deliberada de la legislación como motor del progreso.

En comparación con los países europeos, el Japón de mediados del siglo pasado atravesaba por un subdesarrollo técnico y científico significativo. Sin embargo, sus dirigentes comprendieron que aquel subdesarrollo era el causante del atraso que ostentaban. Por ello, diseñaron una política tecnológica sumamente interesante, mediante la cual conjugaron acertadamente los factores positivos y negativos de la transferencia de tecnología ${ }^{19}$.

avance, sin embargo, aun siendo obvio y sencillo, bastaba. Existiendo un mínimo de realización inventiva, procedía la concesión. En Alemania, contrariamente, la creación inventiva no sólo debía ser tal —novedosa y con carácter industrial- sino también poseer altura inventiva tal que implicase estar por encima de las expectativas del técnico experto en el oficio. Es así que podían presentarse invenciones que, aun siendo nuevas o ingeniosas, no accediesen a la patentabilidad por el hecho de ser susceptibles de fácil creación por algún técnico medio.

${ }^{17}$ La decisión del 3 de setiembre de 1878 del «Reichsoberlandesgericht», resolvió negativamente la eventual posibilidad de proteger objetos de utilidad práctica con la ley sobre dibujos y modelos de 1876. Ver al respecto: RAMELLA, Agustín. Tratado de la Propiedad Industrial. Madrid: Hijos de Reus, 1913, t. I., p. 405. DÍAZ VELASCO, Manuel: Los modelos de utilidad y la protección de invenciones menores, p. 170.

${ }^{18}$ Sobre la política tecnológica del Japón en este período, se puede consultar: «Estudios monográficos sobre la transferencia de tecnología: La política del Japón en materia de transferencia y desarrollo de tecnología antes de la guerra (18681937)». Estudio de la secretaría de la UNCTAD. Documento TD/B/C.6/26.

${ }^{19}$ Ibid., pp. 1-2: «La solución que buscó el Japón de antes de la guerra fue la de aceptar el doble filo como tal y aprovechar al máximo los beneficios del filo positi- 
Antes de la introducción del sistema de patentes, en 1885, y la adhesión a la Unión de París, en 1899, la política de desarrollo interno del país era adversa debido a los tratados comerciales resultantes de la transferencia de tecnología ${ }^{20}$. La renegociación de los mismos comenzó a operar luego de los acontecimientos descritos ${ }^{21}$. En sus inicios, el sistema de patentes no contempló el modelo de utilidad. Incorporado el Japón al Convenio de París, comenzó un acelerado proceso de introducción de tecnología de avanzada. Dicha tecnología estaba muy lejos de ser alcanzada por la industria japonesa, no sólo por razones económicas, sino también por su alto grado de desarrollo y complejidad. Se hizo entonces evidente que no convenía proveer de un mismo nivel de protección tanto a los titulares de las grandes invenciones extranjeras como a los de las «pequeñas» invenciones domésti$\operatorname{cas}^{22}$.

En este orden de ideas, fue utilizada deliberadamente la legislación como instrumento de política tecnológica al promulgarse la ley de modelos de utilidad. Con la protección dual, las avanzadas invenciones del extranjero estaban lo suficientemente cubiertas como para ser exportadas al Japón sin temor alguno, en razón de la ley de patentes. Al mismo tiempo, la mente creadora del ciudadano japonés era estimulada para la invención. Tam-

vo (o sea la transferencia de tecnología) para reforzar la capacidad competitiva internacional de la industria del país, a fin de compensar a la larga, las desventajas del filo negativo (las relaciones económicas en condiciones desiguales)».

Se dice que el filo negativo significó un costo caro en el experimento, ya que «... se tuvo que aceptar tratados comerciales desiguales con las potencias occidentales en el decenio de 1850». Los dos componentes de estos tratados eran la denegación de la autonomía arancelaria al Japón y la concesión de éste de derechos de extraterritorialidad, en virtud de los cuales los comerciantes extranjeros podrían establecer casas comerciales para manejar el comercio exterior japonés. Hasta 1911, el Japón no pudo conseguir la plena autonomía arancelaria. Y durante gran parte de ese período de medio siglo, su comercio exterior estuvo controlado también por las casas comerciales extranjeras. En 1877, por ejemplo, los comerciantes extranjeros efectuaron alrededor del $95 \%$ de las exportaciones e importaciones, y en 1900 todavía efectuaron más del $60 \%$...

20. Ver nota anterior.

${ }^{21}$ TAKEHIKO, Suzuye: «Distinguishing Japan's utility model and patent laws». En: A practical approach to patents, trademarks and copyrights. Volume 2 (4), (september 1982), p. 222.

${ }^{22}$ SHOJI, Matsui, ob. cit., p.7. 
bién se producía la acumulación de recursos tecnológicos básicos, los cuales eran alentados y protegidos por la ley de modelos de utilidad.

Las empresas extranjeras comenzaron a exportar su tecnología al Japón, mientras que las firmas nacionales fomentaban sus propios recursos tecnológicos en aquellas invenciones ${ }^{23}$. Esta tecnología básica, susceptible de protección por la ley de modelos de utilidad, consistía, entre otras cosas, en el mejoramiento de aquellas sofisticadas invenciones. Esto, mediante su adaptación o conversión a otras aplicaciones ${ }^{24}$.

\subsection{Modelo de utilidad y patente de invención}

\subsubsection{Exclusión de procedimientos}

La primera distinción que fluye del estudio comparativo radica en el tipo de invenciones protegido por cada institución. La doctrina italiana ha afirmado que los inventos son encasillables dentro de dos categorías: invenciones de producto e invenciones de procedimiento ${ }^{25}$. La invención de procedimiento consiste en el nuevo método o proceso de fabricación industrial de un objeto ya conocido. La invención de producto tiende directamente a satisfacer necesidades humanas, mientras que la invención de procedimiento, dado su contenido instrumental, no es otra cosa que un medio. En términos del beneficio de monopolio, la invención de procedimiento otorga exclusividad en el empleo del método de obtención, mientras que en la invención de producto se confiere la facultad de producción y venta, cualquiera que sea el medio con que se obtiene ese producto.

\section{Ibid, p. 8.}

24 TAKEHIKO, Suzuye: «Utility Model Law and Patent Law as Distinguished». En: Japan patents and trademarks, No 28 (1981), p. 1.

${ }^{25}$ CERQUEIRA, Joao, Tratado da Propiedade Industrial. 2da. ed. Sao Paulo: Ed. Revista dos Tribunais, 1982, t. I., pp. 287-304.

Este autor, al referirse a los diversos tipos de invenciones, detalla no sólo las dos referidas (invenciones de producto e invenciones de procedimiento), sino también la «aplicación nueva» y la «combinación». La aplicación nueva es el empleo de agentes, 6rganos y procesos conocidos para la obtención de un producto o resultado diferente de aquel para cuya obtención tales medios son empleados. En cambio, la combinación, si bien es una modalidad de aplicación de medios conocidos, no re- 
Sale a la luz, al descubrirse esta clasificación, una clara distinción entre las invenciones patentables y los modelos de utilidad. De la lectura de las diversas leyes fluye con claridad, como primera conclusion, que la protección que confiere el modelo es sólo para objetos corporales. La exigencia de corporeidad excluye del ámbito de protección todo lo que sea procedimiento. Se trata, de la palabra «modelo»: ella implica a primera impresion siempre un ente corporal, por lo que un procedimiento se resiste a ser considerado como tal. En cambio, la patente de invención claramente puede proteger invenciones tanto de producto como de procedimiento.

Las invenciones de procedimiento - considerando que no son instrumentos de trabajo ni objetos de uso práctico, o, más claramente, que no se representan en forma espacial- evidentemente no pueden ser protegidas como modelos de utilidad. Sólo algunas de las invenciones de producto pueden ser catalogadas como modelos. La propia naturaleza del procedimiento, el cual implica siempre una regla respecto a la conducta humana, descarta toda posibilidad de plasmarlo en una realidad material. Esta prohibición no se extiende en ningún caso al producto resultante de una invención de procedimiento. Si éste cumple con los requisitos necesarios, podrá obtener entonces el resguardo como modelo. Interesa destacar que el modelo de utilidad podría proteger indirectamente una invención de procedimiento. Tal caso se daría cuando la forma espacial del objeto protegido como modelo revelara un único procedimiento para lograrla.

La imposibilidad de conceder títulos de modelos de utilidad para invenciones de procedimiento siempre ha desatado polémicas. Sin embargo, ellas nunca han sido ampliamente difundidas. Desde nuestra perspectiva, el desinterés por cuestionar la institución se debe a la fuerza de la tradición jurídica alemana, la cual, por su peso doctrinario y amplio prestigio internacional, ensombrece y disuade cualquier intento de crítica a su sistema jurídico normativo ${ }^{26}$.

quiere originar efectos diferentes. Importa precisar que cada ley puede establecer diversos tipos de invenciones; sin embargo, la clasificación bipartita es la más indicada, ya que supone la corporeidad o incorporeidad de la idea creativa.

${ }^{26}$ En este sentido, la experiencia de quien escribe ha derivado en esta conclusión, la cual fue corroborada a posteriori por la lectura del artículo que sobre modelos de utilidad escribiera Manuel Díaz Velasco, al que hacemos referencia constantemente en mérito a su riqueza juŕdica. De todo el material consultado para la prepa- 
El examen de la institución a lo largo de su vigencia, ha mostrado una paulatina ampliación del campo de acción de los modelos de utilidad ${ }^{27}$. Creemos que esta circunstancia se debió a la limitación terminológica de la institución, la que surgió para proteger novedades de forma que básicamente se manifestaban en herramientas, etc. En todo caso, el verdadero problema es y ha sido el de proteger las invenciones menores, aquellas que no alcanzan el nivel de altura inventiva exigido en la ley de patentes. Desde este enfoque, no hay razones para discriminar a las invenciones que, siendo poseedoras de una altura inventiva reducida, no se manifiestan en formas de-

ración de este trabajo, sólo hemos encontrado tres fuentes en que se cuestiona la imposibilidad de proteger invenciones de procedimiento por vía de los modelos de utilidad. Una es la ya citada, y la segunda un artículo escrito por Robert P. Sabath, titulado «Petty patents in the Federal Republic of Germany: a solution to the problem of computer software protection». En: Patent Law Review (1977), pp. 595-616.

SABATH examina la eventual posibilidad de obtener protección para los programas de computadora mediante el régimen de los modelos de utilidad. Para esto hace un examen de sus rasgos más saltantes. Concluye que el sistema es ideal, puesto que brinda protección acelerada y por tiempo adecuado a las creaciones de programas de computadora. No obstante, y como es lógico, manifiesta que el sistema, tal cual se legisla en Alemania, no permite tal posibilidad. En este sentido afirma: la adopción del requisito de RAUMFORM (forma espacial, manifestación concreta) disminuiría la protección innecesariamente en el área de la tecnología del computer software. Bajo el sistema alemán, la exigencia del «raumform» constituye el mayor obstáculo para el corto patentamiento de los programas de computadora, porque ellos carecen del requisito de forma determinada que exige la ley, no obstante la clara manifestación física que ostentan, sea mediante tarjetas perforadas o fuentes de almacenamiento magnético. El fracaso del sistema alemán de modelos de utilidad para extenderse a la protección de programas de computadora, no obstante la particular adecuación que el mismo brinda a este propósito, resulta en parte de su inercia histórica.

La tercera fuente está constituida por los reportes de los diversos países que trataron el tema de la importancia legal y económica de los modelos de utilidad (AIPPI, Asociación Internacional para la protección de la Propiedad Industrial). Question 83: Legal and Economic Significance of Protection by Utility Models. Zurich, AIPPI, 1985.

${ }^{27}$ DÍAZ VELASCO, Los modelos de utilidad y la protección de las invenciones menores, p. 200. El autor expresa textualmente:

«Todo el proceso posterior de interpretación doctrinal de los textos legales ha sido de constante ensanchamiento, cada vez mayor, de los conceptos iniciales , insosteniblemente estrechos. A pesar de ser evidente que el legislador de 1891 no 
terminadas. De esta manera, las invenciones de procedimiento y sustancias deben ser también amparadas ${ }^{28}$.

Se ha concluido que la distinción más precisa, aunque con limitaciones, entre las invenciones patentables y aquellas susceptibles de protección como modelos de utilidad, es la concerniente al criterio cuantitativo de distinción basado en la mayor altura inventiva de las primeras en comparación con las segundas. El diverso nivel de altura inventiva, más precisamente, el nivel limitado, no es exclusivo de las invenciones manifestadas en formas concretas. Es claro que dentro de la amplia gama de invenciones de procedimiento y sustancias, hay algunas que carecen de la altura inventiva necesaria para acceder a la patentabilidad. Existiendo una protección para invenciones de producto con entidad inventiva reducida, no puede menos que sentirse discriminado aquel inventor que creando nuevos procesos o sustancias de entidad inventiva también reducida, no encuentre protección para sus invenciones.

Interesa destacar que la corriente actual apunta aparentemente en esa dirección. Sobre el particular, son muchos los países desarrollados que, deseosos de instaurar un sistema de protección de invenciones al estilo del modelo de utilidad, concuerdan en que el mismo debiera proteger también a las invenciones de procedimiento. Se ha llegado incluso a sostener el nece-

había pensado en ello, se fueron admitiendo los objetos bidimensionales: los que ofrecían novedades de materia sin novedad alguna de forma; aquellos que no representaban un mejoramiento funcional de otros ya existentes, sino la creación de funciones totalmente nuevas e independientes de la anterior; y en fin , las combinaciones y funciones mecánicas mismas; todo ello cualificado y transmutado por la posibilidad legal, inicialmente negada, de que la interpretación del contenido de los modelos de utilidad se hiciera con la aplicación del principio propio del campo jurídico de las patentes de invención, de la protección automática de los equivalentes técni$\cos »$.

${ }^{28}$ Ob. cit., p. 201. El autor continúa diciendo: «Sin embargo, aunque fue mucho lo avanzado, no fue todo lo debido. La última consecuencia lógica del proceso ha de ser la de conceder a toda clase de invenciones menores la protección que hoy se otorga a los llamados modelos de utilidad. No hay razón fundamental que se oponga a ello. La única efectiva es la de la fuerza de una tradición legislativa y doctrinal de ya más de medio siglo.

Y acaba de afirmarse que esa protección debe concederse a toda clase de invenciones menores porque tampoco hay ningún fundamento para excluir de ella a aque- 
sario cambio de denominación del instituto para desechar dudas de toda cla$\mathrm{se}^{29}$.

A pesar de la lógica de esta posición, pueden argumentarse como objeciones - y sobre todo para los países en desarrollo - la falta de experiencia doctrinal, jurisprudencial, legislativa y práctica en lo relativo al tema del nivel inventivo. A diferencia de lo que sucede en países desarrollados -donde es posible recurrir a abundantes fuentes de consulta, además de contarse con amplia experiencia-, en el seno de nuestros países parece necesario buscar criterios objetivos de diferenciación entre los modelos y las patentes. Uno de ellos es, precisamente, el que ha suscitado controversia en este punto.

En nuestra opinión, esta postura se basa en consideraciones que, si bien aparentemente ciertas, no contribuyen del todo a justificar la exclusión de las invenciones de procedimiento del régimen de modelos. Nos parece que la adopción del sistema forzosamente ha de motivar constante elaboración doctrinal, jurisprudencial y legislativa que propicie soluciones adecuadas. Si a esta consecuencia sumamos las cada vez más cercanas vinculaciones entre los diversos países, en mérito de acuerdos intergubernamentales, y la utilización de medios comunicativos y de consulta mucho más eficaces, los riesgos, creemos, son infundados.

Por otro lado, no olvidemos que la distinción basada en el tipo de invenciones protegibles por cada instituto resuelve solamente un aspecto del problema. En efecto, es cierto que quedan descartadas las invenciones de procedimiento, pero, dentro de la amplia gama de invenciones de producto,

llas invenciones que, siendo incorporales o de procedimiento, sean menores porque no alcancen el nivel de patentabilidad exigido por las mayores, pero sean invenciones».

${ }^{29}$ Al ser tratada la cuestión 83 (ob. cit.), los reportes de países como Canadá, Dinamarca, Israel y Noruega manifestaron su complacencia por la introducción del sistema, con la salvedad de que él debiera proteger también invenciones de procedimiento. Sobre el cambio de nombre, el reporte del grupo israelí, elaborado por Michael Cohn, expresa: «El término modelo de utilidad sugiere solamente la protección de productos, y desde el punto de vista del grupo israelí, aquélla debe ampliarse para las invenciones de procedimiento. En vista de ello, tal vez más adecuado sería buscar una denominación distinta». 
siempre se va a derivar la discusión hacia el grado de mérito inventivo. Como vemos, forzosamente se tendrá que arar en aquel campo.

\subsubsection{Criterios diferenciadores}

La doctrina italiana ha elaborado una serie de criterios diferenciadores. La razón de ser de dicha elaboración doctrinaria se sustenta en la normativa ${ }^{30}$. Ella permite la presentación simultánea de patentes y modelos de utilidad, pero sólo faculta la concesión de un título. La autoridad administrativa debe decidir que solicitud procesa. Ardua es la labor si consideramos que la distinción entre los dos sistemas de protección puede resultar muy complicada en determinados $\operatorname{casos}^{31}$.

Existen criterios cualitativos y cuantitativos. Los primeros pretenden explicar las diferencias en razón de la esencia distinta de un instituto frente al otro. Los segundos consideran que la distinción reside en la diferente proporción de los elementos característicos de cada figura. Dentro de los primeros, tenemos: amplitud de la idea tutelada; relaciones de causalidad; preexistencia e inexistencia, y solución de un problema técnico. Dentro de los segundos pueden detallarse los siguientes: resultado industrial; utilidad, y altura inventiva. El examen, aunque sucinto, de estos criterios, no debe faltar en ningún estudio realizado sobre los modelos de utilidad.

\subsubsection{Cualitativos}

\subsection{Amplitud de la idea tutelada}

La amplitud de la idea tutelada, como criterio distintivo, sostiene que el modelo de utilidad protege la forma externa del objeto y que la patente de in-

${ }^{30}$ Italia acogió el instituto mediante el real decreto del 25 de agosto de $1940 \mathrm{~N}^{\circ}$ 1411. El concepto de modelo de utilidad está contenido también en el artículo 2592 del Código Civil.

${ }^{31}$ Como muestra de la dificultad para distinguir entre la invención y el modelo de utilidad, basta tener en consideración el título que utiliza FRANCO BENUSSI en un estudio que hace al respecto: «Incertezze della distincione fra invenzioni e 
vención ampara el contenido de la ideación ${ }^{32}$. Mientras que en el modelo, para ser forma útil, la forma reivindicada debe estar siempre asociada al producto, en la patente la invención puede ser percibida incluso desincorporada del producto que eventualmente la admite.

La gran objeción que se le puede hacer a esta pauta diferenciadora consiste en que existen inventos que se plasman o contienen en una forma exclusiva, o imposible de ser modificada profundamente sin variación del resultado. Adicionalmente, tanto en el modelo como en la patente se protegen invenciones, vale decir, resultados de la actividad creadora; y en ambos concurre el producto intelectual, el cual no es una obra espiritual individualizada mediante la unión de la idea y la forma, sino una idea en cuanto tal $^{33}$.

\subsubsection{Relación de causalidad}

La relación de causalidad, como criterio distintivo, sostiene que el invento es patentable en tanto revela conexiones ocultas, relaciones antes inaccesibles. El mismo supone una nueva combinación de fuerzas naturales, de forma tal que se produce una actuación en el campo de las relaciones de causalidad que rigen los fenómenos del mundo físico y químico. Distintamente, en el caso de la invención amparada por el modelo, el nuevo resultado que se obtiene es producto de la aplicación primera de procesos causales ya conocidos ${ }^{34}$. En otras palabras, mientras que en la invención, además de resolver un problema técnico, se revela una relación de causalidad apta para producir efectos industriales antes inexistentes, en el modelo de utilidad no hay captación de nuevos principios de causalidad ni tampoco incremento del conocimiento científico ${ }^{35}$.

Modelli di Utilita». En: Separata del Notiziario Giuridico del Unione Industriale di Torino $\mathrm{N}^{\circ}$ 6-7 (junio-julio, 1970).

${ }^{32}$ BONASI BENUC, Tutela della forma nel Diritto Industriale. Milano: 1963, p. 309.

${ }^{33}$ BAYLOS, ob. cit., p. 540.

${ }^{34}$ Ver: LEDESMA, Julio, «El modelo de utilidad». En: Enciclopedia Jurídica OMEBA, Buenos Aires.

${ }^{35}$ DI GUGLIELMO, ob. cit., p. 76, $\mathrm{N}^{\circ} 218$. 
El criterio distintivo que reside en atribuir sólo a los inventos la adquisición de un nuevo principio causal, no es valedero. Tanto en el modelo como en el invento se desarrollan siempre relaciones causales. Por otro lado, los principios científicos no son los protegidos por la exclusiva ${ }^{36}$. Todos los inventos forzosamente generan la producción de efectos industriales nuevos. Constantemente se desarrollan una serie de soluciones técnicas que no suponen el hallazgo de principios modificativos de una relación de causalidad entre fuerzas naturales y efectos industriales. Se trata de creaciones técnicas de gran contribución que denotan, mediante aplicaciones desconocidas de lo existente, un gran talento. La simplicidad no desautoriza a la invención y puede suceder que la idea inventiva, por sus sencillez, llegue a parecer obvia. Es precisamente esa gran simplicidad la que proyecta el genio creador $^{37}$. Piénsese, por ejemplo, en una cortadora de césped automáti$\mathrm{ca}$, que en su concepción inicial es un invento, sin lugar a dudas, a pesar de proyectarse sobre bases ya conocidas.

\subsection{Preexistencia e inexistencia}

Los tribunales italianos han sostenido que la patente implica objetos inexistentes o desconocidos, mientras que el modelo se refiere a cambios formales en objetos ya conocidos, es decir preexistentes ${ }^{38}$. La diferencia surge por la circunstancia particular de generar siempre la invención nuevos servicios u objetos, y por la de que los modelos se limitan a mejorar el fruto de objetos no propios. Este criterio se conoce como el de la preexistencia e inexistencia.

A primera impresión, lo expuesto parece convincente. Sin embargo, quedan sin resolver varios puntos. En efecto, cabría preguntarse qué ocurre con las patentes de perfeccionamiento o adición. En ellas se realizan modificaciones de objetos ya conocidos, que no pierden sus características fundamentales, y tenemos a cambio inventos y no modelos de utilidad. Por otro lado, de considerarse que las patentes de invención son exclusivas de las creaciones nuevas, prácticamente no sería posible otorgarlas a ninguna invención, ya que todas, de una u otra manera, siempre se sustentan en crea-

\footnotetext{
${ }^{36}$ ASCARELLI, ob. cit., p. 611.

${ }^{37}$ BREUER MORENO, ob. cit., t.I., p. 73.

${ }^{38}$ LEDESMA, ob. cit., p. 632.
} 
ciones previas. Ocurre que la gran mayoría de invenciones de producto recogen muchos principios de los objetos ya existentes, al punto que podría válidamente argüirse que se trata de modificaciones de los mismos y no de implementos con autonomía o partida de nacimiento propia.

El juicio que se refiere a la novedad se basa en nociones vigentes de la sociedad y, consecuentemente, está condicionado por la relevancia que en determinado momento se atribuya a las innovaciones introducidas en el objeto preexistente. Por lo tanto, el grado de innovación puede permitir determinar que el objeto ha sido ya tan modificado, que deja de ser él mismo para convertirse en uno nuevo ${ }^{39}$.

\subsection{Solución de un problema técnico}

Un sector importante de la doctrina italiana sostiene que, a diferencia de la invención, en la cual se da la solución de un problema técnico, en el modelo hay solamente un aporte creador. Lejos de resolver problemas técnicos, sólo hace más cómodos y/o eficaces los productos industriales ${ }^{40}$. Este criterio distintivo es rebatido al considerarse que la técnica —entendida como el obrar encaminado a la transformación de las fuerzas naturales con el objetivo de satisfacer necesidades humanas ${ }^{41}$ - se refleja por igual en el modelo de utilidad - que confiere mayor comodidad en la aplicación de un objeto-, como en aquel invento de excesiva sofisticación. En ambos hay un objetivo único: satisfacer necesidades humanas. La intensidad varía, pero el fin es el mismo ${ }^{42}$.

${ }^{39}$ BERCOVITZ, Alberto, «Consideraciones sobre la novedad y la altura inventiva en las patentes de invención y en los modelos de utilidad». En: Actas de Derecho Industrial. Madrid: Montecorvo. T. I. (Año 1974), p. 272.

${ }^{40}$ BERCOVITZ, ob. cit., p. 260.

${ }^{41}$ BERCOVITZ, Requisitos positivos de patentabilidad en el Derecho alemán. Madrid, 1969, p. 340.

${ }^{42}$ BAYLOS, ob. cit., p. 537. Este autor, al momento de hacer la caracterización general de lo que es una invención, declara expresamente: «... No son otra cosa en realidad que soluciones técnicas nuevas para la satisfacción de necesidades humanas mediante el dominio de las fuerzas naturales. Este concepto general comprende lo mismo las invenciones que lo que en ciertas legislaciones se denomina modelos de utilidad, y que son simplemente invenciones menores, invenciones en que la solu- 


\subsubsection{Cuantitativos}

\subsection{Resultado industrial}

Toca el turno a los criterios cuantitativos. El primero de ellos refiere que el resultado industrial —entendido como efecto funcional de los medios empleados por la creación-, siendo de alto grado, corresponde a un invento amparable por el régimen de patente. En caso contrario - es decir, si el resultado industrial es de grado inferior-, la creación sería susceptible de protección como modelo de utilidad ${ }^{43}$.

Como crítica a esta posición, cabría precisar que es postura mayoritaria en la doctrina sostener que el mérito del resultado industrial no es relevante en la creación. Basta que él marque un pequeñísimo adelanto sobre lo conocido para que se produzca el invento ${ }^{44}$. Adicionalmente, una creación con un resultado industrial notable que se proyecta a un sector muy reducido, ¿es acaso más apreciable que aquella otra que - si bien ostentando un resultado industrial insignificante- es utilizada por un sector muy amplio?

\subsection{Utilidad}

El segundo criterio cuantitativo es el de la utilidad. La utilidad es el fin de la invención, o aptitud del resultado conseguido por la ejecución de la regla inventiva, para satisfacer alguna necesidad humana ${ }^{45}$. La aptitud de la creación, para ser catalogada como invento patentable o como modelo, recae en la mayor o menor utilidad que ella genera. A mayor ventaja, la creación se acerca a la patente.

ción técnica radica por lo general en la modificación formal introducida a un objeto ya conocido».

${ }^{43}$ COLICA, «Observazioni sui brevetti per modelli di utilita». Rass. Prop. Ind. 1948, N ${ }^{\circ} 211$; AULETT y MANGINI, p. 324, ver en: GIUDINI, Gustavo y HASSAN Sandro, «Diritto Industriale "Commentario"», IPSOA, 1984.

${ }^{44}$ BREUER MORENO, ob. cit., t.I, p. 112.

${ }^{45}$ BERCOVITZ, Requisitos positivos de patentabilidad en el Derecho alemán, p. 132 . 
Aparentemente, podría parecer que hay similitud entre la utilidad y el resultado industrial; sin embargo, se trata de dos rasgos de naturaleza distinta en la invención. En efecto, si bien son categorías muy vinculadas, el resultado industrial se centra sobre todo en la solución que se obtiene por la puesta en práctica de la invención, mientras que la utilidad consiste en la ventaja que proporciona este mismo resultado una vez obtenido.

La invención es susceptible de tutela aun cuando no satisfaga exigencias humanas en formas más ventajosas (utilidad), dado que lo que la caracteriza es su efecto, hasta entonces desconocido (resultado industrial). Adicionalmente, la variedad de necesidades humanas relativiza el criterio de utilidad en la nueva creación ${ }^{46}$. Finalmente, el requisito de utilidad no guarda relación alguna con el concepto de invento ni de modelo, ya que lo que las leyes demandan es una utilidad potencial o determinada capacidad para conferir utilidad ${ }^{47}$.

Teniendo la nueva creación utilidad- entendida ésta en función del objeto a que se destina-, ya no cabe hacer comparaciones. No se puede decir que un invento es más útil que otro, porque teniendo ambos razones de operar distintas y solucionando problemas relativos a necesidades humanas diversas, es innecesaria cualquier comparación. La mayor o menor utilidad de un invento o modelo, sólo puede equipararse a creaciones destinadas al cumplimiento de las mismas funciones.

\subsection{Altura inventiva}

Finalmente, es importante referirse al último criterio cuantitativo de diferenciación: la altura inventiva. Se trata de un requisito positivo de patentabilidad, que se encuentra consagrado en un sinnúmero de legislaciones sobre patentes ${ }^{48}$. La aportación creadora que manifiesta es compensada

${ }^{46}$ DI GUGLIELMO, ob, cit., p. 47.

${ }^{47}$ FRANZOSI, Mario, «La Nozione de Modello de Utilitá». En: Volume Celbrativo del XXV Anno de la Rivista di Diritto Industriale, Milán: Dott. A. Giuffré Editore, 1977, p. 421.

48 BERCOVITZ, Requisitos positivos de patentabilidad, p. 303.

Al establecerse que la altura inventiva es un requisito positivo de patentabilidad, se está sosteniendo que ella debe juzgarse con base en la regla técnica cuyo carácter 
con el monopolio. De no contar la creación con ella, se reconocerían derechos de exclusiva a hallazgos obtenibles sobre la base del patrimonio técnico existente, frente a lo cual el beneficio no tendría sentido como estímulo y recompensa para la creación que supere las fronteras de la técnica ${ }^{49}$.

La altura inventiva, para efectos de las leyes de patentes, debe significar, sobre la técnica precedente, un adelanto que escape a las posibilidades del técnico medio, provisto de los conocimientos generales en la materia de que se trate ${ }^{50}$. En las leyes de modelos de utilidad, se diferencia el invento del modelo mediante la apreciación del nivel o altura inventiva. Serán modelos las creaciones que no alcancen la entidad inventiva requerida para las invenciones patentables.

La inventiva debe entenderse relacionada con el avance sobre el estado de la técnica y la facilidad con que ella ha operado. Estas dos variables determinan la relevancia de la creación, con fines de aportar la pauta determinante para elegir el tipo de protección. Una de las legislaciones que con más claridad recoge este principio diferenciador es la japonesa ${ }^{51}$. Enfrentando a la doctrina imperante, se aventura a definir la invención ${ }^{52}$. Ésta se

inventivo se quiere mostrar, prescindiendo en absoluto de quién sea su autor, cuáles son sus conocimientos y cuál ha sido el esfuerzo necesario para el establecimiento de esa regla. Los factores que sean extraños a la regla técnica considerada en sí misma no tienen relevancia para los efectos de establecer el juicio sobre la altura inventiva.

49 ASCARELLI, ob. cit., p. 499.

${ }^{50} \mathrm{BERCOVITZ,} \mathrm{Requisitos} \mathrm{positivos} \mathrm{de} \mathrm{patentabilidad} \mathrm{en} \mathrm{el} \mathrm{Derecho} \mathrm{alemán,}$ p. 305 .

${ }^{51}$ Ley 121 del 13 de abril de 1959. Ver: Industrial Property (revista) (abril 1981).

52 GAMA CERQUEIRA, ob. cit., t. I., p. 211 . Justificando la razón por la que la mayoría de las leyes no definen la invención, expresa que, siendo el concepto de ella más técnico que jurídico, resultaría temerario intentarlo. Por su parte, José Gómez Segade (La modernización del Derecho español de patentes, Madrid, Montecorvo, 1984 , p. 50) menciona el criterio del Consejo Federal suizo, el cual manifiesta que «la apreciación de los datos que constituyen una invención depende en gran medida de juicios de valor. En consecuencia, una definición acertada por la ley correría el riesgo de ser superada por el desarrollo de la técnica, y de limitar excesivamente la libre apreciación del juez, lo que impedirá de esta forma, que la ley alcance su objetivo, que es favorecer la industria». 
conceptualiza como la creación de ideas técnicas altamente avanzadas que utilizan las leyes naturales. En contraste, la ley de modelos de utilidad, al definir el dispositivo, expresa que es la creacion de ideas técnicas que utili$z a n$ las leyes naturales ${ }^{53}$. Se observa que la distancia entre ambos sistemas de protección reposa en la contingencia de lo altamente avanzado. Adicionalmente, la ley japonesa hace otra distinción al referirse a la patentabilidad y registrabilidad de las invenciones y modelos de utilidad, respectivamente. La invención que pudiera haber sido hecha fácilmente por persona experta en la técnica no es patentable, mientras que el dispositivo que muy fácilmente haya sido hecho por igual sujeto no es registrable como modelo ${ }^{54}$. En otras palabras, los modelos de utilidad tienen un nivel más bajo de altura inventiva que las patentes, y por ello se supone que son fáciles de obtener. La diferencia en este nivel, entre lo «fácilmente» y lo «muy fácilmente», es sutil. En definitiva, ningún criterio que sirva de patrón ha sido bien establecido ${ }^{55}$.

Es claro que este criterio de distinción conlleva problemas. Su subjetividad no ha impedido, sin embargo, que la aplicación en concreto de las normas para los modelos de utilidad siempre se asiente sobre la base de que el modelo protege hallazgos de grado inferior al invento tutelable por patente.

Como consecuencia, prácticamente todas las leyes otorgan un plazo de exclusiva más reducido, además de brindar simplificaciones y menores controles en la fase de registro.

De acuerdo con esta pauta diferenciadora, la legislación italiana atribuye a los modelos un carácter innovador, el cual se diferencia del

${ }^{53}$ La ley de modelos de utilidad japonesa, ley 123 del 13 de abril de 1959 (ver: Industrial Property, junio de 1981), dispone que su propósito es fomentar los dispositivos mediante la promoción de protección y utilización de los mismos relativos a la forma o construcción de artículos o a la combinación de ellos, así como contribuir al desarrollo de la industria.

${ }^{54}$ Artículo 3, inc. 2 de la ley de modelos de utilidad y artículo 29 , inc. 2 , de la ley de patentes.

${ }^{55}$ INABA, Yoshiyuki, «Patents and utily models». En: Joumal of the Japanese Group of AIPPI (International Edition, junio 1984), p. 52. 
inventivo $0^{56}$. La diferencia existente entre la invención y la innovación es extremadamente difícil de establecer en la práctica. Desde un punto de vista técnico, se puede definir a la invención como aquella creación del espíritu humano caracterizada por el hecho de resultar, no de una combinación lógica, sino más bien intuitiva de ideas precedentes. En contraposición, el modelo de utilidad es una innovación no inventiva. Una creación que no resulta de una combinación intuitiva, sino que proviene de una combinación lógica $^{57}$.

El carácter intuitivo o no intuitivo de la elaboración creativa determina el tipo de innovación por producirse. La diferenciación permite visualizar la distinta graduación de la proyección mental previa o necesaria para el desarrollo de la creación. Confrontando lo lógico con lo intuitivo, es claro el mayor esfuerzo mental que requiere la elaboración intuitiva. Mientras lo lógico significa aquello que es consecuencia natural y legítima, lo intuitivo es, en cambio, la penetración a la realidad misma, que brinda el conocimiento absoluto. La intuición es la aprehensión íntegra de un objeto en forma simultánea y no de manera sucesiva en sus diversas partes. Es más, al oponerse la intuición a la inteligencia, se sostiene que ésta no penetra en la esencia de las cosas sino que se limita a establecer relaciones entre ellas, por lo que sólo tiene fines prácticos dirigidos a actuar con eficacia, sin permitir un adentramiento en la realidad de dichas $\cos ^{58}{ }^{58}$.

Prosiguiendo con esta concepción, se llega a establecer una distinción entre las innovaciones no inventivas, es decir, aquellas provenientes de una combinación lógica de ideas. Al respecto, las innovaciones que han demandado un alto contenido de raciocinio serían innovaciones en sentido estricto, mientras que aquellas que han requerido de un caudal menor serían simples novedades. El problema es que la innovación y la novedad limitan muy estrechamente como para poder clarificar una división neta, además de recurrirse, por cierto, a criterios extraños al concepto de innovación, tales

${ }^{56} \mathrm{El}$ artículo 2 del real decreto de 1940 expresa:

«... El efecto de la patente para modelos de utilidad se extiende a los modelos que consiguen igual utilidad, siempre que realicen el mismos concepto innovadon».

${ }^{57}$ FRANZOSI, $o b$. cit. (Se expondrá su posición en las siguientes líneas).

${ }^{58}$ La intuición, como categoría filosófica, escapa a los límites de nuestra investigación. Nos limitamos a ser descriptivos al pretender esclarecer una distinción utilizada por la doctrina. 
como utilidad, dificultad, etc. Es evidente que en la práctica será muy difícil admitir que un hallazgo es fruto de la intuición antes que del razonamiento, para efectos de encuadrarlo como invento o innovación. De todas formas, de lo dicho hasta aquí se desprende una clasificación tripartita: invento tutelable por patente, innovación tutelable por modelo de utilidad, y novedad no tutelable.

\subsection{El modelo de utilidad y el modelo industrial}

\subsubsection{Criterios diferenciadores}

La separación entre los modelos de utilidad y los modelos industriales está referida al objeto de protección que a cada figura se destina. Los modelos industriales son objeto de protección únicamente en cuanto a la novedad de formas que ostentan, y representan solamente creaciones de valor estético. Los modelos de utilidad, en cambio, amparan la novedad traducida en un aumento de la utilidad técnico-industrial.

La configuración exterior del objeto marca la diferencia entre los modelos de utilidad y los industriales. En el modelo industrial, cobra importancia esencial aquella parte del producto que influye en el sentimiento estético del consumidor, es decir, la configuración externa. Distinto es el caso del modelo de utilidad, en el que lo importante es el elemento «forma», que, ya sea interna o externa, faculte la solución de un problema técnico ${ }^{59}$.

Se ha sostenido también que la correcta distinción entre estos modelos no puede construirse solamente respecto a los diversos fines o efectos logrados. Se debe tratar, por el contrario, de analizar la naturaleza de la idea creadora correspondiente a cada institucion ${ }^{60}$. En este orden de ideas, se sumaría a la clásica distinción aquella que refiere al modelo industrial como producto de una idea de adaptación original, frente al modelo de utilidad, determinado por la idea de innovación original.

59 OTERO LASTRES, José Manuel, «El resultado útil como rasgo conceptual del modelo de utilidad». En: Actas de Derecho Industrial. Madrid: Montecorvo, t. VI (años 1979-1980), p. 189.

${ }^{60}$ LEDESMA, ob. cit., pp. 633-634. 
La adaptación original debe ser entendida como producto de una forma plástica especial. Ésta, colocada sobre un objeto conocido, ha de brindar una forma externa particular, o generar una armonía producto de la fusión de lo inmaterial (la forma particular) con lo material (el objeto o producto al cual se adapta). En el modelo de utilidad, en contraste, habría solamente una innovación materializada. Ella consistiría en el esfuerzo del creador para sortear dificultades o producir resultados prácticos eficaces que permitan distinguir el objeto innovado de su predecesor.

Algunas de las diversas diferencias existentes entre las dos figuras son las siguientes: multiplicidad de sistemas para proteger los modelos industriales, frente a un sistema único de protección del modelo de utilidad: el requisito de visibilidad; la mayor amplitud del modelo de utilidad frente al modelo industrial, y el empleo de nuevos materiales.

\subsubsection{Multiplicidad de sistemas frente al sistema único de protección del modelo de utilidad}

La protección del modelo industrial recoge principios distintos en muchos países. En Francia, por ejemplo, rige la acumulación absoluta, que consiste en proteger la creación simultáneamente por el derecho industrial y por el derecho de autor. En España y en Alemania, opera la acumulación restrictiva. Es decir, que sólo determinados modelos industriales podrán ser protegidos por el derecho de autor. Así, sucede que las creaciones de «arte aplicado» son protegidas, además del derecho industrial, por el derecho de autor. Mediante un juicio de valor sobre la obra, se establece si ésta es «arte aplicado» y, consecuentemente, si es susceptible de protección por la ley de derechos de autor, dado que cuenta con entidad y mérito artístico. En Italia, en cambio, opera un sistema que niega la vinculación entre las leyes de derecho de autor y de propiedad industrial, en lo concerniente a la protección jurídica de los modelos industriales. En dicho país, los modelos industriales sólo son protegidos por el derecho industrial, Finalmente, el derecho belga anterior a la ley de propiedad industrial de los países del Benelux, establecía que la protección a los modelos industriales debía darse en la orbita del derecho de autor.

De los cinco países citados, tres contemplan en sus legislaciones la protección de los modelos de utilidad (Alemania, España e Italia). No cabe 
duda de que el sistema de protección que regula su tratamiento es el relativo al derecho industrial. La asimilación del modelo de utilidad al derecho de patentes permite que en los países donde se regula la figura estudiada, ella se desenvuelva dentro del derecho industrial.

En el modelo de utilidad, la naturaleza de la creación nunca va a generar dudas respecto al sistema de protección que a él corresponda. En cambio, vemos que no hay unanimidad en lo que concierne a la disciplina que debe regular la protección de los modelos industriales. Pareciera que los mismos no se hallan aún bien delimitados, ya sea dentro de la propiedad intelectual o de la propiedad industrial.

\subsubsection{Requisito de visibilidad}

El requisito de visibilidad tiene en el modelo industrial un carácter imperativo. Si bien los modelos industriales y de utilidad protegen creaciones de forma, en los segundos ésta no requiere ser perceptible por la vista. En cambio, la existencia de la emoción estética, propia de las creaciones ornamentales, necesita apariencia exterior y visible. Por ello, el modelo industrial siempre debe ser dirigido al sentido de la vista.

El valor estético de los modelos industriales, frente a la utilidad técnico-industrial de los modelos de utilidad, nos lleva a concluir que los caminos por los que puede transitar el modelo de utilidad son más variados que aquellos correspondientes a los modelos industriales. Ocurre que, al expresarse el modelo industrial por el sentido de la vista, solamente aquello que varíe la percepción visual del objeto puede alcanzar la protección legal ${ }^{61}$. Diferente es el caso del modelo de utilidad, en el que se reivindica la mejora funcional, la cual puede ser producto de una forma particular, de una estructura distinta o disposición novedosa, de una composición diversa, etc. ${ }^{62}$.

${ }^{61}$ La ley japonesa de diseños $N^{\circ} 125$ del 13 de abril de 1959, alude expresamente al sentido de la vista.

${ }^{62}$ Las leyes de los diversos países que regulan el modelo de utilidad no son uniformes. Citando algunas como ejemplos, tenemos las siguientes categorías reivindicables:

Filipinas: forma, configuración, construcción o composición. 
Es así que la mejora técnica puede no ser perceptible visualmente o, en todo caso, no modificar la forma del objeto mejorado en comparación con su antecesor.

Al sustituirse el material mediante el cual está compuesta una creación de forma, en principio no está desarrollándose un cambio en la configuración y, por lo tanto, no habrá nuevo modelo industrial. Cosa distinta ocurre en el modelo de utilidad. Es factible que la mejora funcional radique precisamente en la utilización de un nuevo material. Es decir, que el nuevo material que va a utilizarse sea el factor productor de la nueva mejora funcional.

Se debe comprender que aquello que se protege en el modelo de utilidad es, en primer lugar, la mejora técnica, que generalmente va acompañada de un cambio de forma. Sin embargo, en el empleo del nuevo material -que es una excepción al principio de cambio de forma como creador de una nueva utilidad - no hay cambio de forma aparente, pero sí una mejora y, como tal, es susceptible de protección.

En los modelos industriales, el principio que rige es el de la forma perceptible, generadora de un nuevo efecto estético. La utilización de un nuevo material, por sí sola, sin un cambio en la configuración del objeto que lo incorpora, escapa a la protección. Las reivindicaciones en el modelo industrial sólo apuntan a la forma, mientras que en el modelo de utilidad pueden ser objeto de un cambio de forma, de construcción o de composición $^{63}$.

\subsection{Modelo de utilidad y petty patent}

En las doctrinas norteamericana y anglosajona, el modelo de utilidad se denomina petty patent (pequeña patente). La justificación es sencilla, ya que

Polonia: forma, construcción, montaje permanente.

Alemania: nueva configuración, adaptación o disposición.

${ }^{63} \mathrm{El}$ primer caso en que se discutió el cambio de materiales en modelos de utilidad se dio en Alemania en relación a ballenas de corsé. Las nuevas ballenas eran de celuloide, mientras que las anteriores eran naturales, es decir, provenientes de las lá- 
la protección que brinda el modelo, por su corto plazo de monopolio o por su relativa rapidez en la concesión -característica no uniforme en todas las legislaciones-, pareciera remitir a una figura similar a la patente, pero de rango inferior. En 1979, Australia introdujo un sistema de petty patent mediante enmiendas en el «Patent Act» de 1952. La forma con que opera el mismo, además de las singulares características, impide hoy en día seguir haciendo equivalencias entre las denominaciones modelo de utilidad y petty patent.

Se acuño el término petty patent siguiendo las recomendaciones del Report relating to utility models ${ }^{64}$. A criterio de los integrantes del comité que desarrolló el reporte aludido, mucho más sentido tenía la utilización de esa denominación, dadas las características recomendadas para aquella forma de protección. El solo hecho de ser susceptibles de tutela invenciones de procedimiento vía el petty patent - lo que como veremos sucede en Australia- justifica descartar el término modelo de utilidad.

Antes de detallar los rasgos particulares, es interesante referirnos a las

minas córneas que tienen las ballenas en la mandíbula superior. El tribunal sentenció declarando que el cambio de material no podía ser protegido mediante el registro de un modelo de utilidad, y que la protección solamente se concedía a las nuevas disposiciones caracterizadas por una forma externa novedosa. (Sentencia del 8 de julio de 1895 del Tribunal del Imperio).

Tres años después, el tribunal cambió de criterio. Se trataba de un registro para modelo, relativo a un espéculo uterino y rectal, en el que la novedad consistía en el revestimiento exterior de celuloide. La elasticidad y tenacidad de aquel material atenuaban o suprimían los efectos perjudiciales del contacto del espéculo con las superficies orgánicas. El tribunal, a pesar de reconocer que el celuloide era un material conocido, así como sus cualidades, y que no se había presentado una variación de formas en el nuevo espéculo, optó por conceder el registro. (Sentencia del 19 de febrero de 1898 del Tribunal Supremo alemán).

${ }^{64}$ El título completo de este documento es «Designs Law Review Committee: Report relating to utility models (second term of reference)», 1973.

La alusion a «second term of reference» (segundo término de referencia) obedece al pedido hecho por el Parliament of the Commonwealth of Australia de considerar la introducción en Australia de provisiones legislativas con respecto a los modelos de utilidad; en caso de ser ello sugerido, recomendar las provisiones que se cree deben ser incluidas en la legislación (p. 7 del documento). Este pedido fue posterior al primero relativo a un estudio de la Ley de diseños. 
razones por las que fue introducido. Como bien lo expresa el reporte mencionado anteriormente, no existía en Australia una brecha significativa en la protección prevista por las patentes, diseños y legislación de derechos de autor. No existía tampoco un número significativo de artículos que ameritasen protección y que al mismo tiempo fuesen incapaces de obtenerla en alguna forma ${ }^{65}$.

Sin embargo, el comité quedó impresionado por las solicitudes que recibió sobre la necesidad de una forma distinta de proteccion: pequeños artículos o simples «artilugios» requerían obtener una sencilla, rápida y economica protección. Las solicitudes partían de la premisa de que si bien pequeños artículos son a menudo susceptibles de acceder a protección, el sistema de patentes, en la práctica, no proveía de una suficientemente rápida y no costosa protección. Consecuentemente, a pesar de que el comité no vio una brecha significativa en la protección disponible, sí se percató de la existencia de una en la disponibilidad de protección válida bajo las disposiciones sobre patentes, en ese momento imperantes ${ }^{66}$.

El petty patent fue introducido en el «Patent Act» asimilándose al concepto de patente. El artículo 6 del Patent Act fue modificado para in-

${ }^{65} \mathrm{Ob}$. cit., párrafo 18 . El comité llegó a concluir que no había una brecha significativa en la protección disponible en Australia para invenciones, similar o equivalente al vacío que se produjo en Alemania por los requerimientos de alto nivel inventivo de la ley de patentes. Manifestó que en lo que al sistema australiano de patentes atañe, es posible obtener patentes de invención para creaciones que sólo podrían acceder a la protección del modelo de utilidad si se siguiera la normativa alemana.

${ }^{66}$ Ibid., párrafo 20. A pesar de que en 1969 el sistema de concesión de patentes fue modificado para hacerlo más rápido, se advirtió una serie de contratiempos para el pequeño inventor. Para el inventor que carecía de medios para actuar en el mercado por sí mismo, la única salida era recurrir a un fabricante. A menudo ocurría que aquel fabricante no estaba preparado para recibir la invención si ella no había obtenido una protección de patente. Fue manifestado que era a menudo imposible para el pequeño inventor colocar su invención en el mercado lo suficientemente rápido para prevenirse de infractores, particularmente de aquellos con más medios disponibles para la colocación del producto en el mercado.

En estas circunstancias, se alegó que el inventor estaba a menudo incapacitado financieramente para explotar la invención por sí mismo, o para comenzar acciones contra los infractores una vez que obtuviera su patente. 
cluir dentro de la patente al petty patent. Asimismo, se identificó a las patentes convencionales, distintas al petty patent, como «standard patent».

El procedimiento de aplicación a un petty patent requiere de una descripción detallada de la invención. La descripción detallada debe describir aquella, incluyendo el mejor método conocido por el aplicante para su funcionamiento o ejecutabilidad. La diferencia con el contenido de las descripciones que corresponden a las patentes standard radica en que mientras para éstas es válida la pluralidad de reivindicaciones que definen la invención, en el petty patent opera una limitación en el número de ellas. Toda descripción detallada de un petty patent debe finalizar en una reivindicación única que defina la invención.

El plazo de duración de la exclusiva es de doce meses, comenzando desde la fecha de concesión del título. Es posible una prórroga por cinco años más si se solicita con un mes de anticipación a la expiración del primer año. En suma, el período del monopolio puede alcanzar los seis años. En lo que concierne a la solicitud de extensión a cinco años más, debe remarcarse que dentro de los once meses posteriores a la concesión del petty patent, terceras personas tienen el derecho de notificar la existencia de razones que justifiquen la revocación de la patente. Si al considerarse los argumentos se ve en efecto que son ciertos, se rehúsa la concesión de la próro$\mathrm{ga}^{67}$.

${ }^{67}$ Las razones sobre las que terceras personas pueden informar a las oficinas de patentes para solicitar la revocación del título son las siguientes:

- que el aplicante no es la persona con derecho sobre el petty patent;

-que el petty patent fue obtenido en contravención de los derechos del solicitante o de alguna persona bajo o mediante la cual el solicitante reivindica;

-que la descripción de la invención correspondiente al petty patent no sea totalmente clara y que no incluya el mejor método conocido por el solicitante para el desarrollo de la invención. Asimismo, que la descripción no termine en una única reivindicación que define la invención;

-que el petty patent no reivindique una invención;

-que la reivindicación del petty patent sea obvia y no envuelva un paso inventivo, teniendo en cuenta lo que es conocido y usado en Australia en la fecha de prioridad de la reivindicación o antes de ella;

- que la invención contenida en la reivindicación del petty patent sea el objeto de una reivindicación válida con prioridad anterior contenida en una descripción del petty patent; 
El procedimiento de concesión no requiere de examen previo. Tan solo se procede a analizar la aplicación en cuestiones puramente formales ${ }^{68}$. De acuerdo con la legislación, la facultad de aceptarse o rechazarse la aplicación depende del convencimiento que se tenga acerca del cumplimiento de los requisitos del Patent Act. En caso de no ser alcanzados en la aplicación, la oficina de patentes notifica al titular a fin de que presente las enmiendas necesarias.

Si el comisionado de la oficina de patentes acepta la aplicación, se procede al sellado, lo que significa la obtención del título. Si bien el plazo comienza a correr desde el sellado, al publicarse la concesión en la gaceta oficial, terceras personas podrán advertir y notificar a la oficina de patentes la existencia de elementos que afecten la validez del petty patent.

El «Franki Committee» ${ }^{69}$ vio la necesidad de una protección menos onerosa que la disponible bajo la ley de patentes de la época. Con ese afán, las tarifas propuestas con respecto a las aplicaciones del petty patent son las mismas que las requeridas en los standard patents. Sin embargo, los costos totales de obtención de tutela por el petty patent son sustancialmente menores, ya que no hay más pagos que hacer. No hay tarifa de examen de fondo y tampoco pagos adicionales por la extensión del monopolio ${ }^{70}$.

-que la invención contenida en la reivindicación del petty patent no sea nueva en Australia en la fecha de prioridad de esa reivindicación.

Cabe destacar que estas mismas razones pueden ser presentadas para solicitar la revocación de una «patente standard».

${ }^{68}$ La aplicación es aceptada si se cumple con los requisitos del Patent Act y no se trata de una invención no patentable de acuerdo con el artículo 155. El tenor de éste es como sigue: «El comisionado puede rehusarse a aceptar una aplicación y la especificación o la concesión de una patente:

- para una invención cuyo uso sería contrario a la ley;

- sobre la base de que las especificaciones reivindiquen como invención: a) una sustancia capaz de ser usada como alimento o medicina para seres humanos o para animales, sea para uso interno o externo, y sea una mera mezcla de ingredientes conocidos; b) un procedimiento que produce esa sustancia por mera mezcla».

${ }^{69}$ FRANKI — juez del Commonwealth Industrial Court - fue presidente de la comisión que desarrolló el «Report relating to utility models».

${ }^{70}$ KILDEA, P.F., « Petty patents», p. 2. Lectura hecha el 6 de abril de 1979 en la Sociedad Victoriana de Propiedad Industrial. 
El tránsito de un sistema de protección a otro, es decir, la conversión de un standard patent a un petty patent, o viceversa, se permite mediante aplicaciones divisionales. El procedimiento de aplicación para el segundo de ellos puede entonces ser hecho mediante una aplicación directa, o mediante una aplicación divisional derivada de una aplicación a standard patent.

Luego de esta breve descripción es fácil extraer algunas conclusiones relacionadas con el modelo de utilidad. En primer lugar, el Patent Act australiano no limita los objetos, categorías o tipos de invención que pueda proteger el petty patent. De esta forma, es posible obtenerse protección distinta a la de las patentes para invenciones de procedimiento. También es claro que no se establecen criterios de altura inventiva diferenciados para cada tipo de patente. Cualquier invención puede acceder indistintamente a cualquiera de los dos sistemas o, lo que es más claro, invenciones que aspiran a ser protegidas por el petty patent pueden llegar a convertirse en standard patent.

\subsection{Procedimiento de concesión}

La sola circunstancia de cumplir una creación inventiva con los requisitos particulares exigidos al modelo de utilidad, no es suficiente para que aquella produzca efectos jurídicos. Se hace necesaria la intervención administrativa a fin de que se conceda el privilegio. La forma como ella opera, sin embargo, no es uniforme en la legislación comparada. Esta circunstancia no sorprende puesto que el trámite administrativo de concesión fue constantemente debatido desde la introducción por vez primera del régimen. El modelo surgió como reacción al riguroso examen alemán de concesión de patentes. Por ello, la nueva especie tutelar, además de las características sustantivas particulares, trajo consigo un nuevo procedimiento de concesión.

\subsubsection{Diversos sistemas de concesión de patentes}

Antes de detallar los diferentes sistemas de concesión de modelos, vamos a pronunciarnos sobre los diversos sistemas de concesión de patentes. Una comprensión a grandes rasgos de la operatividad de estos sistemas nos per- 
mitirá concluir cúal es el que mejor se identifica con el régimen de los modelos de utilidad.

\subsubsection{Sistema de examen previo}

Este sistema de concesión de patentes era el que regía en Alemania al momento de la dación de la ley de modelos de utilidad. La particularidad radica en el examen riguroso de las condiciones de patentabilidad de la invención. En este sentido, se indaga la novedad y la altura inventiva de la nueva creación, además del cumplimiento de los requisitos formales. La comparación de las anterioridades supone un juicio técnico, para el cual es preciso disponer de los antecedentes que revelen el nivel de inventiva mundial. Es necesaria la posesión de una documentación completa para la consulta, además de un plantel numerosísimo de funcionarios técnicos.

\subsubsection{Sistema de libre concesión}

La ley francesa de 1791 y la posterior de 1844 adoptaron el sistema de libre concesión. Éste consistía en otorgar las patentes sin examinar si el invento era patentable o no lo era. El sistema se basa en realizar sólo un examen de forma de la solicitud y de la descripción. Los documentos presentados por el solicitante sufren un examen de forma para comprobar si se ajustan a los requisitos legales, si se da un título que realmente corresponde al invento, si la solicitud se refiere a un solo objeto principal, si se trata de un invento prohibido por la ley, etc. En una palabra, se practica un examen de las formas de la solicitud, sin entrar a considerar si el invento reivindicado es susceptible de obtener la patente.

\subsubsection{Desventajas de ambos sistemas y la aparición de sistemas intermedios}

Como veremos, las desventajas que, por variadas razones, encierran los sistemas de examen previo y de libre concesión, han favorecido el surgimiento de sistemas eclécticos entre ambos extremos. Éstos se caracterizan por recurrir a un examen formal y a un examen parcialmente de fondo para la invención. Los principales sistemas intermedios son el examen diferido, el 
dictamen documental y el sistema de oposiciones. Antes de referirnos a ellos, pasaremos revista a los inconvenientes y ventajas más saltantes de cada uno de los dos sistemas de concesión descritos.

El examen previo proporciona al solicitante una presunción significativa de que su patente es válida, dado que la rigurosidad del mismo actúa como tamiz de inventos no patentables. Sin embargo, equivocadamente, puede rechazar invenciones patentables, y privar de esa forma al inventor del derecho que le corresponde.

Por otro lado, en lo que corresponde a la colectividad, el sistema de examen previo contribuye a que los derechos de exclusiva recaigan sobre invenciones serias. Así se permite eliminar los monopolios injustificados dentro del mercado. De esta manera, el título cuenta con un mayor valor económico, además de una técnica superior.

Un grave e indudable problema es el concerniente a la lentitud con que se resuelve la concesión o denegación de la patente ${ }^{71}$. Además, es objetado por lo excesivamente costoso de su operatividad, tanto para el país como para el solicitante ${ }^{72}$.

El sistema de libre concesión es sencillo, rápido y económico, pero, sin embargo, es objeto de una crítica muy aguda. Sobre él se ha dicho que fomenta la concesión de patentes débiles y de dudoso valor económico ${ }^{73}$.

71 BOTANA AGRA, Manuel, «El sistema de concesión de patentes». En: Hacia un nuevo sistema de patentes. Madrid: Montecorvo, 1982, p. 128.

$\mathrm{El}$ autor, como factores que retrasan la resolución de las aplicaciones, menciona los siguientes: «... la labor de los examinadores es, por su propia naturaleza, ardua y compleja; los resultados iniciales del examen pueden aconsejar al solicitante la modificación de las reivindicaciones; y la decisión del examinador puede ser objeto de recurso por parte del solicitante. Este conjunto de factores favorece la progresiva acumulación de las solicitudes que esperan turno para ser examinadas, lo que con frecuencia conduce a que los solicitantes abandonen su propósito antes de que la Oficina dicte la correspondiente resolución».

${ }^{72} \mathrm{El}$ mantenimiento del plantel de examinadores representa un alto costo en las oficinas de patentes. Adicionalmente, es requerido un complejo fondo de documentación que requiere mucho tiempo y dinero. Estos costos son traspasados en algunos países a los solicitantes de patentes mediante el pago de tarifas obligatorias.

${ }^{73}$ SCHRICKER, G., «El nuevo sistema alemán de concesión de patentes». En: 
También es un hecho cierto que favorece la concesión de patentes para pseudoinvenciones, con la consiguiente invasión, del mercado, de monopolios injustificados ${ }^{74}$.

\subsection{Sistema de examen diferido}

Es el que actualmente rige en Alemania luego de la modificación legislativa de 1967. La característica esencial consiste en que el examen de patentabilidad no es realizado antes de la concesión y no tiene carácter obligatorio. Sólo se realiza a solicitud del interesado o de un tercero.

La solicitud debe hacerse en determinado plazo, y hasta que no se realiza, el sistema funciona de manera similar al de libre concesion: la solicitud es publicada luego de dieciocho meses y se confiere a la invención un resguardo provisional ${ }^{75}$.

\subsection{Sistema de dictamen documental}

Es el sistema que rige en la ley francesa de patentes de 1968. Sus rasgos principales están en el sometimiento de la solicitud de patente a una investi-

Revista de Derecho Mercantil, N 120 (año 1971), pp. 226.

El autor expresa: «El solicitante y los competidores no pueden fiarse de que la patente sea realmente válida. Si alguno quiere adquirir certeza en este punto, debe hacer por sí mismo las investigaciones pertinentes; es decir, tiene que examinar la invención de la misma manera que lo hace la oficina de patentes en el sistema de examen previo».

74 BOTANA AGRA, Manuel, ob. cit., p.129.

75 SCHRICKER, ob. cit., p. 228, sostiene: «Al convencimiento de que no es necesario ni rentable examinar inmediatamente todas las solicitudes, sino tan sólo algunas de ellas, se ha mostrado en la práctica que solamente una pequeña parte de las invenciones para las cuales se solicita una patente llegan a ser explotadas económicamente de una manera relevante. Respecto de muchas invenciones, se reconoce al cabo de cierto tiempo que no son económicamente rentables. Otras invenciones son desvalorizadas por la posterior aparición de invenciones más prácticas que las superan. No obstante, en la lucha contra la competencia, las empresas se ven obligadas a una solicitud inmediata de las invenciones, sin haber tenido la oportunidad de revisar su rentabilidad por falta material de tiempo». 
gación sobre el estado de la técnica. La idea apunta a ver en qué medida la invención carece de novedad o mérito inventivo. Interesa destacar que la oficina de patentes acuerda la concesión o denegación de la solicitud según ella reúna los requisitos formales exigidos y con plena prescindencia del resultado del dictamen.

El dictamen no tiene otro sentido que el de informar al solicitante y a los terceros sobre el estado de la técnica susceptible de afectar la patentabilidad de la invención. Así, la información alerta al solicitante acerca del valor de la invención y determina la conveniencia de renunciar al procedimiento o seguir adelante con él. Para los terceros, el dictamen sirve de pauta para una eventual impugnación de la patente o para la estipulación de un contrato de licencia ${ }^{76}$.

\subsection{Sistema de oposiciones}

Contempla la posibilidad de que terceros intervengan en el procedimiento de concesión de las patentes. La razón de ser está en que los terceros (principalmente los competidores) se encuentran en condición de proporcionar una serie de datos relevantes, a fin de que la oficina de patentes cuente con un criterio adecuado que garantice decisiones acertadas respecto a la posible patentabilidad.

El sistema es acogido por el Convenio de la Patente Europea. Éste establece que las oposiciones deben hacerse con posterioridad a la concesión de la patente, lo que ofrece como ventaja la reducción del número de oposiciones, los procesos de nulidad, etc. Contrariamente, en el supuesto de oposiciones anteriores a la concesión, el solicitante y la oficina de patentes enfrentan una serie de problemas. Sucede que el inventor verá con frecuencia demorado el momento de la concesión, además de arriesgarse a ser acosado por oposiciones impertinentes. Por su parte, la oficina de patentes multiplicará sus esfuerzos de modo innecesario ante la avalancha de oposiciones ${ }^{77}$.

${ }^{76}$ Ver BERCOVITZ, «Nuevas leyes de patentes en Francia y en la República Federal de Alemania». En: Revista de Derecho Mercantil, año 1968, p. 322.

77. BOTANA AGRA, Manuel, ob. cit., p. 134. 


\subsubsection{Diversas alternativas posibles}

¿Cúal es el sistema de concesión que más se adecúa al modelo de utilidad? La respuesta no es fácil, máxime cuando la legislación comparada nos muestra diversidad de alternativas. Esa realidad, en todo caso, sirve para ilustrar la inexistencia de una respuesta única a la pregunta que planteamos. Seguidamente, nos vamos a referir a algunos casos de la legislación comparada.

En Alemania, la oficina de patentes examina la aplicación del modelo sólo en lo concerniente al cumplimiento de los requisitos de la aplicación. En particular, no hay examen de novedad ni de mérito inventivo y progreso técnico, aunque sí se verifica si el objeto es susceptible de protección como modelo. La tutela se hace efectiva desde el registro; sin embargo, cualquier tercero tiene derecho a solicitar la cancelación de la protección concedida. Los argumentos que pueden presentarse son: el incumplimiento de los requisitos de registro, o la existencia de una protección previa - sea de patente o modelo- para la misma creación. Asimismo, el tercero puede, al momento de iniciar la oposición, referirse únicamente al incumplimiento de los requisitos sustantivos de protección: novedad y altura inventiva.

En el Japón, el procedimiento de concesión del título es prácticamente similar al correspondiente a las patentes de invención. Consiste en un examen diferido que se inicia a solicitud de la parte interesada luego de pasados dieciocho meses desde la presentación de la solicitud, la que en sus inicios sólo fue examinada en relación al cumplimiento de requisitos formales. El período para solicitar el examen de fondo es de cuatro años desde la fecha de la solicitud, frente a un plazo de siete años para las patentes. El período más corto obedece tanto a la menor duración del derecho como a la posibilidad de predicción con más facilidad y rapidez de la viabilidad de la explotación del modelo ${ }^{78}$. Esta predicción es determinante en la toma de decisiones relativas a la continuación o paralización del procedimiento de concesión. En todo caso, si no se solicita un examen de la solicitud dentro del plazo de los cuatro años, la aplicación se considera abandonada ${ }^{79}$.

${ }^{78}$ SUZUYE, Takehiko, «Distinguishing Japan's Utility Model and Patent Law», p. 233.

${ }^{79}$ Después de la revisión de 1971 , todas las aplicaciones para registro de mode- 
En España, el trámite de la solicitud de registro de modelos se inicia con un examen sobre el cumplimiento de los requisitos formales de la solicitud y respecto a si el objeto es susceptible de protección como modelo. A diferencia de lo que ocurre con las patentes, el Registro de propiedad industrial no examina ni la novedad ni la actividad inventiva. Si no hay defectos en la solicitud, se notifica al interesado la resolución favorable para la continuación del procedimiento y se dispone la publicación de la solicitud. Después hay un plazo de dos meses en que cualquiera con interés legítimo tiene la posibilidad de oponerse a la concesión, y puede alegar incluso la falta de novedad o de actividad inventiva. De no haber oposiciones, o en caso de ser éstas resueltas favorablemente para el solicitante, el Registro concede la protección.

En Brasil, las aplicaciones son presentadas al Instituto Nacional de Propiedad Industrial y son materia de un examen preliminar de forma. Posteriormente, el aplicante debe solicitar un examen relativo a la novedad y la patentabilidad dentro de los dos años de publicada la solicitud, que ocurre dieciocho meses después de la fecha de iniciado el procedimiento.

\subsubsection{Nuestra opinión}

Nos parece que el examen de fondo, relativo a la novedad y al mérito inventivo, es siempre necesario en una invención. Creemos que los riesgos de conceder monopolios injustificados son mayores que la eventual saturación de una oficina de patentes ${ }^{80}$. Ahora bien, en el caso de los modelos de utilidad, teniendo en cuenta que se trata de un monopolio con plazo de duración más corto, nos parece que la exigencia del examen puede ser soslayada, a la espera de algún tercero que tenga cierto reparo frente a la concesión del título. En este sentido, el procedimiento español de concesión puede servirnos de pauta directriz.

los de utilidad son examinadas sólo a pedido del interesado. Para la obtención de un conocimiento global de la manera en que opera el sistema en el Japón, ver: DOI, Teruo, Utility Model Law of Japan.

${ }^{80}$ Ver HODKINSON, Keith and QUEST, Barry, «Further reform of the patent Law?: The case against petty patents». En: European Intellectual Property Review, 1985 , vol. $7, \mathrm{~N}^{\circ} 4$. 


\section{Segunda parte Régimen derogado de modelos de utilidad}

\subsection{Antecedentes ${ }^{81}$}

En enero de 1982, en el Boletín de la Propiedad Industrial se publicó un artículo titulado «Necesidad de incorporar en la legislación nacional los modelos de utilidad» ${ }^{82}$. Se puede afirmar con fundamento que se trató de la primera publicación que sobre el tema se desarrollaba en nuestro medio. El artículo, de carácter más informativo que doctrinario, proyectaba una iniciativa interesante puesto que señalaba la existencia del régimen y su clara vinculación con la realidad tecnológica nacional. Posteriormente se convirtió en la exposición de motivos del decreto supremo 048-84-ITI/IND ${ }^{83}$.

Según la exposición de motivos de la norma, el modelo de utilidad es cualitativamente distinto de la invención. Él no resuelve un problema técnico y tampoco descubre o reproduce relaciones de causalidad aptas para crear nuevos resultados industriales. Contrariamente, en la creación digna de patente esto sí ocurre.

En la primera parte dijimos que somos contrarios a la distinción entre invenciones patentables y modelos, en lo concerniente a que las primeras importan la revelación de relaciones de causalidad aptas para producir efectos industriales antes inexistentes, y que los segundos son creaciones carentes de principios de causalidad susceptibles de crear productos industriales nuevos. Manifestamos que hay creaciones que presentan soluciones técnicas de gran contribución y que sin embargo no suponen ningún hallaz-

${ }^{81}$ Un completo análisis del régimen derogado se encuentra en:

HALPERIN, Jorge, El modelo de utilidad. Tesis para optar el grado de bachiller en la Facultad de Derecho de la Pontificia Universidad Católica del Perú, Lima 1987.

${ }^{82}$ COMBE DE VERTIZ, Olga, «Necesidad de incorporar en la legislación nacional los modelos de utilidad». En: Boletín de la Propiedad Industrial. Lima, vol. $\mathrm{N}^{\circ} 1$ (enero 1982 ) pp. 3-5. El artículo es reproducción de las páginas 74 a 76 de la obra de DI GUGLIELMO, ob. cit.

${ }^{83}$ La única diferencia existente entre la exposición de motivos y el artículo que aludimos radica en que aquélla está escrita en tercera persona del plural, mientras que el artículo lo está en primer persona. 
go de nuevas relaciones de causalidad, y en mérito a esa gran contribución son amparadas por exclusivas de amplia duración ${ }^{84}$. Referimos que, a nuestro entender, más se adecúa a la realidad de la institución el criterio cuantitativo de distinción basado en la diversa altura inventiva de las creaciones técnicas. A lo largo del estudio realizado, se ha desprendido que la corriente actual propugna que la distinción debe realizarse en aquel nivel, y es precisamente ese criterio el que más eco ha encontrado en la legislación comparada.

El considerando de la norma detallaba la existencia de un vacío en la legislación de propiedad industrial al no contemplar el modelo de utilidad. Sostuvo que el régimen era adecuado para incentivar la capacidad creativa nacional, y finalizaba denunciando que muchas solicitudes no podían ser amparadas legalmente por no cumplir con los requisitos suficientes para alcanzar los títulos de patente de invención ${ }^{85}$.

\subsection{El problema de la altura inventiva}

De las circunstancias descritas, solamente era valedera aquella concerniente al desarrollo de tecnología doméstica y el claro incentivo que representa para tal fin el modelo de utilidad. El vacío comentado era sólo aparente y,

${ }^{84}$ Ver supra, 1.3.2.1.2

${ }^{85} \mathrm{El}$ decreto supremo 048-84-ITI/IND refiere textualmente:

«Considerando:

Que, en la legislación vigente sobre Propiedad Industrial se advierte un vacío que es necesario subsanar, pues no se contempla la protección que merece otorgarse a los modelos de utilidad, que constituye una reconocida e importante modalidad del régimen de la Propiedad Industrial.

Que, es conveniente para el desarrollo de la inventiva nacional, proteger las innovaciones que son fruto del ingenio creativo de la mente humana, no sólo porque se traducen en una mayor o mejor utilización de instrumentos, herramientas u otros objetos con beneficio para la colectividad, sino porque tal protección constituye una de las formas de incentivar la capacidad de creación.

Que, actualmente numerosas solicitudes no pueden ser amparadas legalmente, no obstante su utilidad y trascendencia, porque no teniendo las características necesarias para el otorgamiento de una patente de invención, tampoco existe la normatividad específica correspondiente, razón por la cual resulta indispensable dictar las normas del caso...» 
por lo tanto, las solicitudes no amparadas referidas sí debían serlo. Sucede que, de acuerdo con el ordenamiento legal vigente en ese entonces, la patente se concedía a las nuevas creaciones susceptibles de aplicación industrial y a las que perfeccionaban dichas creaciones ${ }^{86}$. Solamente se requerían novedad y aplicabilidad industrial como requisitos positivos de patentabilidad. Puesto que no se exigía altura inventiva en las creaciones que aspiraban a la patente, y teniendo en consideración que los modelos de utilidad son nuevas creaciones con aplicabilidad industrial caracterizadas primordialmente por perfeccionar creaciones técnicas, no habría fundamento por el cual negar al titular de un modelo de utilidad la posibilidad de que aplique a una patente de invención.

Sobre el tema de la protección de invenciones que califican como modelos de utilidad, la legislación internacional ha asumido cuatro posturas diversas $^{87}$ : a) no proteger al invento; b) protegerlo exactamente igual que al gran invento, bajo la denominación común de «invención»; c) protegerlo, pero sólo con la misma amplitud que al modelo industrial, es decir, como pura forma, y d) otorgarle una protección específica distinta de la del invento y de la del modelo industrial.

El primer caso corresponde a aquellos países que exigen altura inventiva a las creaciones técnicas; tal era la situación de Alemania antes de la dación de la ley de modelos de utilidad. El segundo caso es el que operaba en la ley francesa de 1844 ya comentada ${ }^{88}$, y que se repetía en la Decisión 85. El tercer caso consiste en otorgar protección como novedad de forma a la creación técnica ${ }^{89}$ y el cuarto es el que se aplica en la diversidad de países que han adoptado el sistema estudiado.

${ }^{86}$ Artículo 1 de la Decisión 85.

${ }^{87}$ LACRUZ, «El modelo de utilidad y sus diferencias con la patente de invención», p. 115.

${ }^{88}$ Ver supra, primera parte 1.2.1

${ }^{89}$ LACRUZ, «EI modelo de utilidad y sus diferencias con la patente de invención», p. 116. El autor señala textualmente: «En Bélgica, el hallazgo carente de altura inventiva puede protegerse, según la jurisprudencia, como novedad de forma, pese a tratarse de un modelo técnico, ya que la protección a la forma, en principio, prescinde en absoluto de los caracteres técnicos del objeto protegido, cuya imitación, por tanto, es fácil en forma distinta, pues no se protege la realización o el principio mecánico, sino los elementos de forma y configuración que distinguen al objeto». 
De lo dicho, se desprende que el régimen nacional recientemente derogado se había convertido en el único que asumía dos posturas diversas y contradictorias para la protección de las pequeñas invenciones. En tal sentido, era evidente la falsedad de la consideración que sostenía que antes de la promulgación del decreto supremo 048-84-ITI/IND numerosas solicitudes no podían ser amparadas legalmente, no obstante su utilidad y trascendencia, por carecer de características necesarias para el otorgamiento de la patente. Repetimos: de acuerdo con la normativa suprimida, cualquier creación novedosa y susceptible de aplicabilidad industrial podía alcanzar protección legal mediante la patente.

Con un régimen como el anteriormente vigente, los titulares de creaciones que conceptualmente eran modelos de utilidad podían solicitar la tutela de la patente de invención. No cabían argumentos legales para denegar en tales situaciones el trámite de patente. Considerando el beneficio significativamente mayor de la exclusiva de larga duración en la patente de invención, la actitud más adecuada y lógica para el titular de la creación técnica era solicitar ese título.

\subsubsection{Concepto utilizado}

En lo que se refiere al concepto utilizado, la fórmula guardaba relación estrecha con el objetivo de la institución. Era modelo de utilidad, según el artículo 2 del decreto, toda configuración o disposición nueva de elementos o mecanismos de instrumentos, herramientas u objetos que, como fruto del ingenio humano, permitiesen una mayor utilidad de los mismos, su manejo o funcionamiento más fácil, u otra ventaja. En ese extremo, la norma no erró. Se desprende de su lectura el cumplimiento de las tres condiciones del modelo de utilidad, a saber: operar sobre objetos de uso y dominio público; proyectarse y materializarse en forma espacial (configuración o disposición nueva), y destinarse a un nuevo uso o empleo práctico (permitir una mayor utilidad de los mismos, su manejo o funcionamiento más fácil, u otra ventaja).

Algo curioso era que el concepto recogía una exigencia de cierto nivel de entidad inventiva. La referencia al ingenio humano como gestor de la nueva forma útil, así pareció revelarlo ${ }^{90}$. Había, pues, una aparente contra-

${ }^{90}$ El memorándum $N^{\circ}$ 002-DIPI/DP-85, de fecha 10 de enero de 1985, dirigido 
dicción entre las dos normas que regulaban la tutela de las creaciones técnicas. Esto se desprende del análisis riguroso de ambas: la Decisión 85 no exigía altura inventiva como requisito positivo de patentabilidad, mientras que el decreto supremo 048-84 aludía -aunque indirecta y superficialmente- a una cierta altura inventiva necesaria para la obtención del título. De esta manera, y desde el punto de vista puramente legalista, era más difícil obtener la tutela de una invención conceptualizada como modelo de utilidad, que la de aquella susceptible de patente.

\subsection{El proyecto modificatorio de la Decisión 85}

Lo dicho acerca de la altura inventiva se corroboraba luego de examinar el proyecto modificatorio de la Decisión 85. El mismo -resultante de cuatro reuniones del Comité Coordinador de la Red Especializada de Información sobre Propiedad Industrial, organizadas por el SAIT (Sistema Andino de Información Tecnológica)_ ${ }^{91}$ introducía el modelo de utilidad luego de modificaciones previas. Así, el primer cambio propuesto era el del artículo primero de la Decisión: «Se otorgará patente de invención a las nuevas creaciones que impliquen actividad inventiva y sean susceptibles de aplicación industrial. También es patentable el perfeccionamiento de la invención cuando reúna los requisitos de novedad y aplicación, y la solicitud la haga el titular de la patente original».

El artículo primero de la Decisión 85 tenía distinta redaccion: «Se otorgará patente de invención a las nuevas creaciones susceptibles de aplicación industrial y a las que perfeccionen dichas creaciones». Del cotejo de ambos artículos, la modificación de fondo más pronunciada es la inclusión de la altura inventiva. Ella, tal como lo expresaba el artículo tercero del pro-

a la Dirección de Propiedad Industrial por la División de Patentes, en la parte concerniente al tratamiento interno sobre los modelos de utilidad, exigía como requisitos la novedad absoluta, la aplicación industrial y el mérito inventivo.

${ }^{91}$ El Sistema Andino de Información Tecnológica fue creado mediante Decisión 154 de la Junta del Acuerdo de Cartagena. Las reuniones de la Red Especializada de Información sobre Propiedad Industrial comenzaron en setiembre de 1982 (la primera). El proyecto al que hacemos referencia es producto de la cuarta reunión. No obstante, la idea de incorporar los modelos de utilidad data de las primeras reuniones (1982 y 1983). 
yecto, se configuraba cuando «... sus características (las de la invención) esenciales para un entendido en la materia superan las soluciones técnicas conocidas, y si además dicha invención no se deriva de manera evidente del estado de la técnica» ${ }^{92}$.

Con la inclusión del concepto de altura inventiva, recién guardaba sentido la regulación de los modelos de utilidad como sistema diverso al de las patentes de invención. Es precisamente sobre el punto de altura inventiva que fue sentida aquella inclusión como justificada si se proyectaba su regulación para la protección de las invenciones menores de nivel tecnológico más sencillo ${ }^{93}$.

${ }^{92}$ De esta forma, el proyecto recogía la fórmula más común para conceptualizar la altura inventiva, cual es la de tomar como referencia el conocimiento del técnico entendido en la materia. Así, que habrá invención cuando un técnico medio colocado frente a idéntico problema no pudiera resolverlo.

${ }^{93}$ Las observaciones sobre la modificación de fondo del artículo 1 de la Decision 85 son las siguientes:

«Inclusión del concepto de "altura inventiva" en el artículo 1 de la Decisión 85.

En el Taller de Trabajo efectuado en Quito, algunas oficinas nacionales competentes solicitaron complementar el artículo 1 de la Decisión 85 con el concepto de "altura inventiva" como uno de los requisitos positivos objetivos para obtener en la Subregión la patentabilidad de las invenciones.

En el mencionado artículo 1 de la Decisión 85 no se consideró necesario incluir el requisito de altura o actividad inventiva por cuanto se estimó que estaba implícito al señalarse que solamente "las nuevas creaciones" son patentables. No obstante, se han creado problemas de interpretación en los Países Miembros que contemplaban en sus legislaciones nacionales el requisito de altura inventiva. Por tanto, se sugiere adicionar el artículo 1 de la Decisión 85 con el requisito de la altura o actividad inventiva. Esta inclusión se justifica, con mayor razón si se acepta la patentabilidad en la Subregión de los llamados "modelos de utilidad" para proteger invenciones menores con nivel tecnológico más sencillo.

En consecuencia, se sugiere una nueva redacción para el artículo 1, incluyendo el concepto de "actividad inventiva".

Con esta redacción se estaría exigiendo que todo invento, para que sea patentable, deba reunir los siguientes requisitos: a)novedad; b)actividad inventiva; $y$ c) aplicación industrial».

Extraído de: «Cuadro comparativo de las modificaciones incluidas en el proyecto de reformas a la Decisión 85» (Documento sin referencias bibliográficas obtenido en la Junta del Acuerdo de Cartagena).

En España se ha mantenido esta postura frente al requisito de altura inventiva y 


\subsection{La residencia}

Las deficiencias del régimen se extendieron más allá del problema de la altura inventiva. Una disposición sumamente criticada fue la contenida en el artículo primero. En él se exigió como condición ineludible la calidad de residente en el país del titular del modelo. Esta disposición fue única en su género en la legislación comparada ${ }^{94}$. ¿Cuál es el tratamiento que se debió dar a los titulares de modelos de utilidad no residentes en el país, es decir, a los inventores extranjeros? Puesto que es ilogico pretender que un inventor alemán o italiano, por citar algunos, fueren a obtener la residencia a fin de conseguir el título, no quedó más que concluir que los extranjeros no accederían a este tipo de protección. Para aquéllos, sólo quedaba la opción de solicitar una patente de invención. La exigencia de residencia pudo determinar un claro perjuicio para los inventores locales, puesto que se les limitaba la protección para modelos de utilidad por el propio régimen, mientras que para similares extranjeros se accedía a la regulación de patentes.

como condición ineludible en toda ley de patentes, a fin de que guarde sentido la regulación de los modelos de utilidad.

Sobre este punto es de sumo interés la crítica que formulo el Instituto de Estudios Políticos al régimen de modelos de utilidad ya derogado. En la obra Reforma del Derecho de patentes español (pp. 25 y 26), se expresa: «Respecto a los "Modelos de Utilidad", es sabido que su creación en Alemania obedeció a una necesidad provocada por el hecho de que el sistema de patentes de aquel país, de riguroso examen administrativo previo a la patentabilidad y de la novedad, se basaba en que la invención, para ser protegida, ha de representar un cierto "nivel inventivo", exigencia en virtud de la cual todas estas otras invenciones menores, generalmente consistentes en la alteración de la forma de objetos ya conocidos, para conseguir con ello una mayor utilidad en el uso a que vienen destinados, quedaban privadas de tutela, por no alcanzar esa "altura inventiva" que constituye un requisito de patentabilidad en aquel país. Para ellas se estableció un régimen de concesión diferente, en que la tutela se otorgaba sin previo examen administrativo y el plazo de duración de la exclusiva era más corto. Ninguna de estas razones abonaban en cambio su creación por el Estatuto, en cuanto que el régimen español no da entrada al requisito de patentabilidad de la "altura inventiva..."».

94 Del análisis de la legislación comparada se desprende que no hay ninguna ley que tenga un principio similar. A lo más, legislaciones como la polaca y la de Taiwán disponen que las solicitudes extranjeras sean admitidas de acuerdo a la reciprocidad. Es decir, dependiendo del trato que reciban las solicitudes de modelos de utilidad de aquellos países en la nación a la que pertenece el inventor solicitante. En 
Esta exigencia fue resultado de interpretar equivocadamente los alcances de la norma, las estadísticas y su utilización por inventores domésticos. La sola e importante consideración de ser el modelo de utilidad un claro vehículo para el desarrollo de tecnología nacional, y mayormente usado por inventores nacionales, no descarta la posibilidad de que el mismo sea también utilizado por inventores extranjeros, quienes ven en el sistema una alternativa para proteger la invención fuera de sus fronteras.

Las claras contradicciones y errores descritos, reveladores del sinsentido del primer intento legislativo sobre modelos de utilidad, justificaron plenamente el radical cambio que a continuación exponemos ${ }^{95}$.

\section{Tercera parte Análisis de la actual normativa}

\subsection{La Decisión 313}

\subsubsection{El capítulo II}

El capítulo II de la Decisión se refiere a los modelos de utilidad. Consta de cuatro artículos que refieren la definición, las exclusiones, la remisión al régimen de patentes de invención, y el contenido del derecho.

El artículo 53 precisa el concepto: se concede patente de modelo de utilidad a toda nueva forma, configuración o disposición de elementos de algún artefacto, herramienta, instrumento, mecanismo u otro objeto, o de alguna parte del mismo, que permita un mejor o diferente funcionamiento, utilización o fabricación del objeto que lo incorpora, o que le proporcione alguna utilidad, ventaja o efecto técnico que antes no tenía.

El artículo 54 está referido a las exclusiones. Se dispone que no pue-

esta línea, la norma anterior no permitió que un inventor nacional pudiera obtener un título en los referidos países.

95 Todos estos problemas son analizados en:

HALPERIN, Jorge, "El modelo de utilidad», enero 1988, № 19 Informativo Legal Rodrigo. 
den ser objeto de una patente de modelo de utilidad los procedimientos y materias excluidas de protección por la patente de invención. De igual forma, no se consideran modelos de utilidad las esculturas, obras de arquitectura, pintura, grabado, estampado o cualquier otro objeto de carácter puramente estético.

El artículo 55 dispone la aplicación del régimen de patentes de invención consagrado en la Decisión en todo aquello que fuere pertinente.

El artículo 56 refiere, en cuanto al contenido del derecho, un plazo de exclusiva de diez años, contados desde la fecha de presentación de la solicitud.

\subsubsection{Transformación o cambio de modalidad}

La ubicación del modelo de utilidad entre la patente de invención y el modelo industrial, y el concepto próximo entre estas figuras, hace necesario permitir, en caso de errores de encuadramiento en que incurra el solicitante, modificar los términos de la solicitud. Cabe decir que, en lo que al objeto de protección atañe, un objeto amparable como modelo de utilidad puede serlo también mediante patente de invención siempre que tenga altura inventiva suficiente. Esta realidad determina que en muchos países tanto las leyes de patentes como de modelos de utilidad dispongan normas que regulen las prácticas simultáneas y alternativas en la concesión de los títulos de protección. La estrecha identificación entre las dos instituciones así lo exige. Puesto que la ley no se pronuncia sobre el particular, lo expresado en la Decisión marca las pautas que deben seguirse.

La sección III de la Decisión, bajo el título «De las solicitudes de patentes», regula en los artículos 17, 18 y 19 la transformación de la solicitud de dos maneras: solicitud de transformación del propio solicitante, y sugerencia de la autoridad administrativa. En el primer caso, el peticionario solicita, en cualquier momento previo a la publicación, la transformación de su solicitud a otra modalidad de la propiedad industrial para proteger el mismo objeto. En la segunda situación, la autoridad administrativa, en cualquier momento del trámite, como consecuencia del examen de la solicitud, puede proponer al peticionario el cambio de modalidad, y éste tiene el derecho de rechazar o aceptar la propuesta. Si sucede lo primero, se continúa la tramita- 
ción en la modalidad solicitada originalmente. Aceptada la transformación o la propuesta de cambio, se aplica el procedimiento que corresponda a la nueva solicitud.

La falta de regulación sería peligrosa en este punto, debido a que en la eventualidad de optarse erróneamente, en el caso de una invención susceptible de modelo de utilidad, por la protección de la patente de invención y no ser ésta concedida, el titular de la invención ya no contaría con protección alguna. Sucede que una vez presentada la primera solicitud, su contenido pasa a formar parte del estado de la técnica. No se podría descartar, entonces, la posible denegación de la solicitud del modelo de utilidad aduciéndose falta de novedad.

\subsubsection{Disposiciones complementarias y consideraciones finales}

Es claro que estos artículos no son suficientes para regular adecuadamente el régimen. La técnica legislativa de aplicar las disposiciones sobre patentes en lo que fuere pertinente crea, sin lugar a dudas, una serie de cuestionamientos. Más aún si se considera que en temas como el procedimiento de concesión, las legislaciones consagran para los modelos de utilidad trámites diferenciados de los de concesión de patentes de invención.

Dos artículos contenidos en el capítulo VI, referidos a disposiciones complementarias, son de necesaria referencia. El artículo 118 faculta a los países miembros a fortalecer y ampliar los derechos de propiedad industrial contenidos en la Decisión. El artículo 119 refiere que los asuntos de propiedad industrial no comprendidos en la Decisión deberán ser regulados por la legislación nacional.

\subsection{El decreto ley 26017}

La Ley general de propiedad industrial, decreto ley 26017 , publicada el 28 de diciembre de 1992, establece el régimen de los modelos de utilidad en el título V. Consta de trece artículos, contenidos en cinco capítulos. A diferencia de la Decisión, la ley no hace referencia a las disposiciones de patentes de invención para la aplicación de aquello que sea pertinente. Con mejor técnica legislativa, taxativamente señala qué artículos del régimen de paten- 
tes de invención son de aplicación. Un examen comparativo de los títulos IV y $\mathrm{V}$, vale decir, de las patentes de invención y de los modelos de utilidad, refleja que ambos contienen los mismos capítulos. La única diferencia está en que el régimen de patentes de invención en el capítulo quinto legisla sobre la licencia obligatoria, mientras que para los modelos de utilidad no se dispone concesión de licencias obligatorias ${ }^{96}$. En suma, el régimen contiene un primer capítulo de normas generales, un segundo referido al procedimiento, un tercero acerca de los derechos que confiere la patente de modelo de utilidad, un cuarto sobre las obligaciones del titular, y un quinto que atañe a la nulidad y caducidad.

Lo que viene a continuación es un examen de las normas. La forzosa referencia a las patentes de invención y a la doctrina posibilitará un cabal entendimiento del sistema alternativo de protección de invenciones que consagra esta especie inventiva.

\subsubsection{Capítulo I Normas generales}

\subsubsection{Novedad}

El artículo 62 de la ley establece una primera distinción entre el modelo de utilidad y las patentes de invención al consagrar la novedad relativa y no absoluta. La redacción es clara: «Se entiende por Modelo de Utilidad a la invención que siendo nueva en el ámbito de aplicación de la Decisión 313...». En otras palabras, basta que la invención a la que se pretende conceder patente de modelo de utilidad sea nueva dentro del espacio geografico en que rige la Decisión. Distinto es el caso de las invenciones que aspiran a la protección de la patente de invención. El artículo 27 de la ley, en su segundo párrafo, establece que son patentables las invenciones nuevas. Esta novedad debe ser mundial o absoluta.

* El artículo 72 de la ley establece que no hay licenciamiento obligatorio para modelos de utilidad. Sin embargo, se condiciona la prórroga de la exclusiva por cinco años a la explotación del modelo. En la legislación comparada, el licenciamiento obligatorio es raro, en razón del corto término del monopolio, sumado a la importancia limitada de estas creaciones. 
La amplitud de la novedad es discrecional en cada legislación. El antiguo Estatuto de propiedad industrial español establecía que en los modelos de utilidad la novedad era relativa, es decir, en el interior del país. Ellos eran nuevos si no habían sido divulgados o practicados en España, a pesar de haber podido ser conocidos en el extranjero. Diferente era la situación de las invenciones susceptibles de patente. En ellas se exigía novedad absoluta, es decir, no podían ser conocidas ni practicadas antes de la solicitud, ni en España ni en el extranjero. Esta misma línea la ha mantenido la actual ley de patentes ${ }^{97}$. De la misma forma se pronuncia la ley de Filipinas y la de los países de la OAPI (Organización Africana de la Propiedad Industrial).

Se ha estimado que la novedad para los modelos de utilidad puede ser exigida en menor medida, o no con tanto rigor como la requerida para las patentes de invención. La alternativa de establecer un régimen de novedad no tan riguroso obedece a la aparente confusión entre novedad y mérito inventivo. La novedad en la invención no es otra cosa que una ficción legal. Ya que la invención representa una avance en la técnica, es comprensible que la novedad que ella implica no pueda ser subjetiva, sino que ha de ser objetivamente determinada. El derecho de patentes tiende a impulsar el progreso de la técnica industrial objetivamente considerada. El único medio de hacer compatible esa finalidad con el principio de seguridad jurídica es establecer un concepto legal objetivo. Puesto que tanto las creaciones con derecho a patente, como aquellas susceptibles de modelo, son invenciones en el fondo, no hay por qué variar el criterio objetivo mediante un tratamiento diferenciado.

${ }^{97} \mathrm{El}$ artículo 6 de la ley actual establece:

Inciso 1.- «Se considera que una invención es nueva cuando no está comprendida en el estado de la técnica».

Inciso 2.- «El estado de la técnica está constituido por todo lo que antes de la fecha de presentación de la solicitud de patente se ha hecho accesible al público en España o en el extranjero por una descripción escrita u oral, por una utilización o por cualquier otro medio»

Por su parte, el artículo 145, inciso 1, sostiene: «El estado de la técnica con referencia al cual debe juzgarse la novedad y la actividad inventiva de las invenciones protegibles como modelos de utilidad, está constituido por todo aquello que antes de la fecha de presentación de la solicitud de protección como modelo ha sido divulgado en España por una descripción escrita u oral, por una utilización o por cualquier otro medio». 
En otras palabras, opinamos que la novedad debe juzgarse con los mismos patrones requeridos en la invención susceptible de patente. El tratamiento diferenciado sólo debe hacerse con relación al mérito inventivo. Para terminar con este punto, queda decir que la normativa derogada - por remisión a la Decisión 85, que establecía novedad absoluta para patentes de invención- exigía novedad mundial.

\subsubsection{Invenciones de procedimiento}

El artículo 63 de la ley faculta a otorgar patente de modelo de utilidad a las invenciones de procedimiento. La Decisión, por su parte, en el artículo 54 señala que los procedimientos y materias excluidas de la protección por la patente de invención no pueden ser objeto de patente de modelo de utilidad.

¿Existe contradicción entre la Decisión y la ley en lo que se refiere a la invención de procedimiento y su posibilidad de ser protegida como modelo de utilidad? La respuesta es negativa, a nuestro entender. Dos son las razones que la justifican: el inciso b del artículo 7, y el artículo 118 de la Decisión.

El inciso b del artículo 7 señala que no son patentables las especies y razas de animales y procedimientos para su obtención. Esto conforma un caso de procedimientos y materias excluidas de la protección por la patente de invención. Puede argumentarse en favor de nuestra tesis que el artículo 54, más que impedir patentes de modelos de utilidad respecto a procedimientos en general, ha deseado que se excluyan de protección solamente los procedimientos y materias excluidas de protección por la patente de invencion; es decir, los precisados en el inciso b del artículo 7.

La segunda razón la constituye el artículo 118 de la Decisión al proporcionar a los países miembros facultades para fortalecer y ampliar los derechos sobre propiedad industrial. La inclusión de invenciones de procedimiento en el régimen de modelos de utilidad es una clara ampliación de derechos.

La norma que consagra el artículo 63 bien puede ser considerada de vanguardia, por romper con la tradición existente. Para ser justificada, deben considerarse las razones que motivaron la introducción primera del régimen. 
Como bien ya ha sido señalado ${ }^{98}$, el surgimiento del modelo de utilidad como sistema alternativo al de la patente de invención obedeció a la necesaria protección de las creaciones técnicas menores. El carácter limitado del tipo de creaciones inventivas tutelables se debió a la estrecha concepción que tuvo el legislador alemán del siglo pasado. En aquel entonces, se entendió como únicas creaciones técnicas, aquellas de carácter corporal y que reivindicaban novedades de forma. La evolución doctrinal posterior ha apuntado siempre a la ampliación del ámbito, inicialmente reducido, de creaciones técnicas tutelables. En esta línea, el siguiente paso va dirigido a conceder la protección de todo tipo de invenciones menores, dentro de las cuales se incluyen los procedimientos.

\subsubsection{Altura inventiva}

El artículo 64 de la ley dispone el nivel inventivo como requisito positivo de patentabilidad en la invención que aspira a protección. El nivel inventivo lo determina el experto en la materia al juzgar si la invención no es muy obvia, muy evidente o de fácil realización. Este nivel inventivo es inferior al consagrado en el régimen de creaciones que aspiran a patente de invención. El artículo 28 de la ley establece que el nivel inventivo exigido lo determina el experto en la materia que confirma que la invención no es un resultado evidente, obvio o de fácil realización ${ }^{99}$.

\subsubsection{Excepciones de patentabilidad}

El artículo 65 de la ley señala que se aplican a los modelos de utilidad las mismas excepciones de patentabilidad previstas en el artículo 29. Es claro que tratándose el modelo de utilidad de una invención, sean extendidos a éste las prohibiciones generales.

Hay creaciones inventivas que, aun respondiendo a las características típicas necesarias para merecer un título de protección, no son reconocidas como bienes inmateriales susceptibles de un derecho absoluto de utilización.

\footnotetext{
98 Ver supra 1.3 .1

99 Ver supra 1.3.2.2.3
} 
Cumplen con los requisitos positivos de patentabilidad, pero en el examen de los requisitos negativos caen en las prohibiciones de patentar establecidas en la ley. Conceptualmente, las excepciones de patentabilidad son aquellas hipótesis en que, no obstante presentarse una verdadera invención, no hay posibilidad de amparo mediante patente.

El artículo 29 de la ley excluye de patentabilidad cuatro tipos de invenciones: las contrarias al orden público o las que sean evidentemente contrarias al desarrollo sostenido del medio ambiente; las especies y razas animales y los procedimientos para su obtencion; las invenciones sobre las materias que componen el cuerpo humano y sobre la identidad genética del mismo; y las invenciones relativas a los materiales nucleares y fisionables.

\subsubsection{Prioridad}

El mismo artículo 65 precisa que es de aplicación a los modelos de utilidad lo dispuesto en los artículos 30, 31, 32 y 33 de la ley. Los primeros tres artículos refieren conceptos de prioridad, y el último, a los casos de invenciones realizadas en relación laboral.

El artículo 30, concordado con los artículos 8 y 9 de la Decisión, plantea la solución de un problema ampliamente discutido. Originariamente, el derecho a la patente puede concederse al primer solicitante $o$ al primer inventor. Otorgar el privilegio al inventor concuerda con un principio fundamental del derecho de patentes al premiarlo y protegerlo como creador de la regla técnica. Crea, sin embargo, el inconveniente práctico de recargar a la oficina de patentes con la obligación de comprobar el hecho. Se retrasa la concesión de la patente y la sociedad queda privada de conocer los términos del invento por el tiempo que demore la comprobación. El sistema del primer solicitante, en cambio, otorga a éste, aunque no sea exactamente el primer inventor, el derecho a la patente. Este sistema puede ser criticado porque no gratifica a quien enriquece el conocimiento técnico, pero presenta ventajas prácticas. Ahorra a las oficinas de patentes la comprobación ya señalada y, consecuentemente, genera la rápida revelación de la regla técni$\mathrm{ca}^{100}$.

${ }^{100}$ GÓMEZ SEGADE, José Antonio, La modernización del derecho español de patentes. Madrid, Editorial Montecorvo, 1984 pp. 105-107. 
La ley se ha inclinado por el sistema del primer solicitante-inventor al establecer que si varias personas han realizado la invención en forma independiente una de otra, el derecho a la patente pertenece a quien haya hecho primero la solicitud o, si fuera el caso, a quien reivindique la fecha de prioridad más antigua. Pero la Decisión, protegiendo al inventor, establece que el derecho a la patente le pertenece y le permite la impugnación judicial en cualquier momento después de publicada la solicitud, y hasta por un lapso de tres años posterior a la concesión de la patente. De igual manera lo protege al contemplarse la nulidad de una patente de invención o de modelo de utilidad obtenida por quien no es su inventor o cesionario: Así lo disponen los artículos 8, 9 y 60, inciso a. Estamos ante una solución híbrida puesto que se arbitran mecanismos que permiten moderar el rigor de los principios descritos.

El artículo 31, aplicable al régimen de modelos, reglamenta el artículo 12 de la Decisión, que regula el derecho de prioridad. La vigencia de la prioridad como institución significa, en principio, que para una misma invención no puede concederse más que una sola patente ${ }^{101}$. Así, entonces, la Decisión dispone que, una vez presentada la solicitud de una creación amparable en un país miembro, o en otro que confiera tratos recíprocos, el solicitante obtendrá el derecho de prioridad por un año para solicitar igual protección en otro país miembro.

La solicitud, entendida como el acto voluntario por el cual el inventor manifiesta su intención de obtener el reconocimiento de un derecho, produce una serie de efectos: el inicio del trámite administrativo; el estado de la técnica que puede ser opuesto; la prioridad frente a solicitudes posteriores de patente o modelo; y en algunas legislaciones, el inicio del plazo de exclusiva. Con la fijación de la fecha de presentación de la solicitud queda delimitado el estado de la técnica oponible a la creación que se busca proteger, por lo que toda descripción o utilización del modelo, previa a la solicitud y por lo tanto ya incorporada al estado de la técnica, se convierte en una circunstancia aniquiladora de la novedad. También se asegura al inventor una presunción de prioridad que le permite impugnar la concesión de cualquier otro modelo que por el mismo invento sea solicitada. Esta facultad de

101 BERCOVITZ, Requisitos positivos de patentabilidad en el Derecho alemán, p. 352 . 
impugnación no es otra cosa que un efecto bloqueante sobre cualquier solicitud posterior.

E1 artículo 32 está vinculado al concepto de la prioridad internacional estatuida por el Convenio de París. El artículo 4 del citado convenio dispone que quien hubiere depositado regularmente una solicitud de modelo de utilidad en alguno de los países de la Unión, gozará, para efectuar el depósito en los otros países, de un derecho de prioridad de doce meses, que corre a partir de la fecha del depósito de la primera solicitud.

\subsubsection{Invenciones realizadas bajo relación laboral}

El artículo 33 se refiere al caso de las invenciones realizadas por asalariados. El tema no escapa al caso de los modelos de utilidad y, como tal, ha sido instituido en la legislación comparada. De esta manera, el modelo realizado por el trabajador contratado para investigar pertenece al empleador, salvo estipulación contraria. Asimismo, si el trabajador no contratado para realizar actividades inventivas se vale de la infraestructura del empleador y de los conocimientos adquiridos en la empresa de éste, el derecho a la titularidad de la invención recaerá en el empleador, quien debe para ello ejercer la opción dentro de los noventa días de realizada la invención. En cualquier otro caso, la titularidad de la invención, no obstante la existencia de relación laboral, corresponde al trabajador inventor.

Este sistema es de aplicación para el caso de invenciones realizadas por profesores o investigadores en las universidades, institutos y otros centros de educación o investigación, salvo disposición contraria contenida en el estatuto o reglamento interno de dichas entidades. Así está dispuesto en el último párrafo del artículo que comentamos.

\subsubsection{Capítulo II Del procedimiento}

En la primera parte hemos descrito las características de los diversos sistemas de concesión de patentes. En la ley, y en relación a las patentes de invención, el procedimiento que se ha escogido es el de examen diferido con llamamiento a oposición. 
Ante una solicitud la oficina administrativa verifica el cumplimiento de los requisitos formales. Éstos, descritos en los artículos 38 y 39 de la ley, se refieren a la documentación que forzosamente debe adjuntarse a toda solicitud: identificación del solicitante y del inventor; título o nombre de la invención; descripción clara y completa; reivindicaciones; resumen; comprobante de pago de derechos; poderes; copia de la primera solicitud de patente si se alega prioridad, y demás requisitos que el organismo competente pueda solicitar.

Concluido el examen, se ordena la publicación del extracto de la descripción del invento y de las reivindicaciones solicitadas (artículo 41). Luego, pueden darse dos situaciones: la observación o la inexistencia de ella. Si sucede lo primero, se faculta al solicitante a contestar la observación y la oficina abre la causa a prueba. La ley manda, en esta situación, desarrollar el examen de fondo de la invención para determinar si la creación reúne los requisitos positivos de patentabilidad: aplicación industrial, novedad y nivel inventivo (artículo 43).

Si no hay observación, la oficina administrativa concede una patente provisional que otorga los mismos derechos que la patente definitiva por un plazo de tres años. Durante este lapso, el titular o terceros pueden solicitar el examen de fondo. Si se solicita el examen, es obligación de la oficina llevarlo a cabo en un año, prorrogable por una sola vez por seis meses. De no terminarse el examen dentro de este plazo, se otorga la patente. Sin embargo, por decreto supremo se pueden establecer las áreas industriales en las que el examen a fondo de patentabilidad sea obligatorio para concederse la patente de invención definitiva. Si no se solicita examen de fondo dentro del plazo de vigencia de la patente provisional, no se concede la patente definitiva y caduca la provisional (artículo 44).

En el caso del modelo de utilidad, el procedimiento es de llamamiento a oposiciones. Si no hay observaciones, la patente de modelo de utilidad se concede automáticamente, sin necesidad de examen de fondo. Si hubiere oposiciones, el artículo 69 refiere que, luego de presentadas, el solicitante contesta, el observante replica y finalmente el solicitante duplica. Como último paso, la oficina administrativa resuelve definitivamente. La resolucion podrá requerir una examen de fondo de la solicitud, o no requerirlo. Es la oficina administrativa, dependiendo de la naturaleza de las observaciones, la que determinará la necesidad de realizarse aquél. Si bien esto último no está 
prescrito en el artículo, debe entenderse que la resolución definitiva podría implicar su realización.

Comparativamente, los términos varían entre los dos procedimientos. En la concesión de patentes de invención, transcurren hasta seis meses desde la solicitud hasta la publicación. Para los modelos, el plazo es de tres meses. En el primer caso, las observaciones se deben presentar dentro de los sesenta días posteriores a la publicación; mientras que en el segundo, dentro de los treinta días. Las contestaciones a aquéllas, en las patentes de invención, se hacen dentro de los sesenta días siguientes. En los modelos de utilidad, en cambio, hay quince días para contestar, quince días para replicar y quince días más para duplicar. La apertura de la causa a prueba, en el caso de las patentes, es por sesenta días; mientras que para los modelos, este plazo ha sido reducido a la mitad.

Finalmente, en el caso de las patentes, el examen de fondo se extiende más allá del plazo de apertura de la causa a prueba, ya que ésta se inicia para determinar la procedencia de la oposición y la ley nada dice respecto al plazo de duración de aquél. En todo caso, habiendo oposición y determinándose su improcedencia, el examen debe forzosamente efectuarse puesto que al actuarse las pruebas se ordena el estudio de la solicitud y su realización. Algo distinto es lo que sucede con el modelo de utilidad, puesto que la oficina administrativa, dentro de los treinta días de presentada la dúplica por el solicitante, resuelve sin obligación de realizar un examen de fondo, tal como ya ha sido observado.

Es claro que el trámite de concesión es sencillo en comparación con el correspondiente a la patente de invención. Hemos señalado en la primera parte, al detallar los procedimientos de concesion aplicables al régimen de modelos, que, siendo un monopolio con un plazo de duración corto, la exigencia del examen o la concesión del privilegio puede condicionarse a la aparición de terceros que la objeten. Por otro lado, siempre está expedita la acción de nulidad en caso de contravenirse las normas sobre patentabilidad y sus requisitos. Así lo dispone el capítulo sexto, referido a la nulidad y la caducidad de la patente, que a tenor de lo preceptuado en el artículo 74 es de aplicación a los modelos de utilidad. 


\subsubsection{Capítulo III \\ Derechos que confiere la patente}

Las distintas leyes que contemplan la especie inventiva del modelo de utilidad, sujetan el contenido de los derechos obtenidos a las reglas relativas a los derechos emergentes de las patentes de invención. Es en este sentido que se otorga un privilegio exclusivo de manufactura y venta del objeto. En otras palabras, se obtiene un derecho exclusivo para la comercialización del producto.

Lo sustancial del derecho subjetivo conferido por la concesión del título de modelo de utilidad radica en el goce exclusivo del fruto de la propia concepción intelectual concretada en el nuevo invento. Esta protección jurídica surge con la solicitud de concesión o con la concesión del título, ya que desde alguno de esos momentos obtiene el inventor el derecho subjetivo de ejercicio exclusivo de la invención e, implícitamente, el de prohibición de uso a los demás.

El contenido del derecho es excluyente, dado que permite al titular impedir a terceros la realización de los actos propios de la explotación del invento. La facultad excluyente constituye la nota característica del derecho. Mediando la intervención administrativa, se concede la prerrogativa de impedir que los terceros hagan uso de la explotación industrial del invento.

La doctrina y la legislación han sido las encargadas de enumerar los actos prohibidos de realización por quienes no son titulares. Se trata de los actos industriales o comerciales que, por referencia directa o indirecta al invento amparado, pueden originar ventajas económicas con independencia de intencionalidad en el lucro. Estos actos pueden ser impedidos en su realización por el titular del modelo, ya que implican una infracción de la exclusiva. Aquí, el titular cuenta con dos alternativas: la vía civil y/o administrativa, y la vía penal. En la primera, se busca el cese de la actividad infractora y una eventual indemnización. En la segunda, dependiendo de la tipificación del acto de infracción como modalidad delictiva, el titular buscará el cese de la infracción, así como establecer la responsabilidad penal que el Estado determine en el infractor.

La facultad excluyente se ve limitada ante algunos supuestos. Se trata de tres circunstancias: los actos realizados en un ámbito privado y con fines 
comerciales; los actos realizados con fines experimentales; y la explotación o posesión anterior de la invención. El primer supuesto es una hipotesis tradicionalmente reconocida por la doctrina y la jurisprudencia, que han venido propugnando que los actos desarrollados en la esfera personal y doméstica constituyen una zona inmune frente a las acciones que la ley atribuye al titular de la patente ${ }^{102}$. En el derecho de patentes, la exclusiva está circunscrita al ejercicio del invento que sale del terreno puramente privado. De este modo, se deriva que la práctica del modelo respecto a todas las formas de ejercicio, es lícita cuando se efectúa con miras a uso personal o privado ${ }^{103}$. La segunda hipótesis comprende las investigaciones estrictamente académicas y las que corresponden a actividades de investigación y desarrollo de una empresa. Si bien es objetable que puedan resultar lesionados los intereses del titular del modelo, no se puede soslayar la necesaria realización de experimentos e investigaciones que tengan por objeto impulsar los avances de la técnica ${ }^{104}$. El tercer supuesto ocurre cuando un tercero, con anterioridad a la fecha de prioridad del modelo, posee o explota el mismo. Es el caso de dos personas que idean al mismo tiempo el modelo, pero independientemente, y sólo una de ellas inicia el procedimiento de concesión necesario.

El primer supuesto está consagrado en el inciso b del artículo 35 de la Decisión, y en el inciso b del artículo 46 de la ley. La segunda hipótesis se regula en los incisos $c$ de los mismos artículos anotados. La tercera situación está contemplada por el artículo 47 de la ley y el artículo 36 de la Decisión. La ley ha omitido en el capítulo tercero del título $\mathrm{V}$ una disposición que precise que los artículos 45, 46 y 47 son de aplicación para el régimen de modelos de utilidad. Sin embargo, ellos sí lo son por efecto de la Decisión. Los artículos precisados son copia textual de los correspondientes a la sección $\mathrm{V}$ de ésta, y su artículo 55 extiende la aplicación de disposiciones sobre patentes de invención a los modelos de utilidad en lo que fuera pertinente.

La temporalidad es una característica particular de los bienes inma-

${ }^{102}$ FERNÁNDEZ NOVOA, La modernización del derecho español de patentes. Madrid, Editorial Montecorvo, 1984, p. 199.

${ }^{103}$ RAMELLA. ob. cit., t. I, p. 179.

${ }^{104}$ FERNÁNDEZ NOVOA, La modernización del derecho español de patentes, p. 200. 
teriales. Dependiendo del tipo de creación intelectual de que se trate, el plazo de exclusiva tiene connotaciones diversas. En el campo de las obras de ingenio, como los inventos y modelos, el progreso cultural y técnico -en cuya promoción encuentra la tutela su justificación última- exige que la creación pueda en definitiva ser utilizada por todos y encontrar en esta general utilización su potenciación. Esta circunstancia justifica la limitación natural en la duración de la exclusiva ${ }^{105}$. La nota de temporalidad, relativa a la protección juŕdica de las creaciones inventivas, se considera fundamental desde el punto de vista del interés común. La perpetuación del monopolio de puras ideas o de soluciones técnicas útiles, causaría grave perjuicio a la sociedad entera, y obstaculizaría de modo intolerable el progreso técnico e industrial ${ }^{106}$.

En materia de modelos de utilidad, es un principio instituido el de conceder el plazo de monopolio por un término menor que el correspondiente a las patentes. Partiendo de la premisa de que el monopolio es una recompensa otorgada al inventor, ésta debe ser proporcional al grado de esfuerzo creativo desplegado en la obra. De esta manera, el nivel de altura inventiva califica el término de duración. A los inventos patentables corresponde un plazo amplio, dada su mayor altura inventiva, mientras que a los modelos de utilidad, que se caracterizan por una menor altura inventiva, les corresponde un término más corto.

Señalar el término adecuado de la exclusiva no es tarea sencilla. La legislación comparada no es uniforme ${ }^{107}$. Por otro lado, las leyes, dependiendo de sus sistemas de concesión, otorgan privilegios con distintas suposiciones de validez. Un sistema de concesión con examen de fondo obligatorio da mayor presunción de validez a un modelo que un sistema que no lo exige $^{108}$. En este sentido, la duración de la exclusiva debe guardar relación con el grado de certeza que se tenga acerca de la validez del título.

${ }^{105}$ ASCARELLI, $a b$. cit., p. 346.

${ }^{106}$ BAYLOS, ob. cit., p. 557.

${ }^{107}$ La legislación comparada no es uniforme en este punto. Los extremos están marcados por Portugal, que establece un plazo de cinco años renovable indefinidamente, y Somalia, que por su parte dispone un plazo de cuatro años desde la fecha de presentación de la solicitud.

${ }^{108}$ En Australia, el término de duración del monopolio del petty patent fue motivo de muchas deliberaciones, y finalmente se optó por el término de un año, prorro- 
El plazo de duración de la exclusiva de acuerdo a la Decisión, es de diez años, contados a partir de la fecha de presentación de la solicitud. Así está dispuesto en el artículo 56. La ley, en el artículo 70, sin contradecir a la Decisión, concede originalmente el monopolio por cinco años. Este plazo es prorrogable, por una sola vez, por cinco años si el titular acredita la explotación del modelo. La prórroga se liga a lo que el artículo 51 entiende por explotación: la elaboración o comercialización, en el caso de invenciones de producto; y el empleo del proceso o la comercialización del objeto obtenido a través del proceso patentado, en el caso de invenciones de procedimiento. Asimismo, la explotación, para que sea inobjetable, debe satisfacer en forma suficiente la demanda del mercado.

\subsubsection{Capítulo IV}

De las obligaciones del titular de la patente de modelo de utilidad

A diferencia de lo que ordena el capítulo similar para las patentes de invención, donde hay pluralidad de exigencias - obligación de explotar la invención y marcado-, esta parte compromete al titular sólo en lo último. El artículo 71 exige el marcado del producto, con la indicación del número de registro colocado luego de la expresión «Modelo de Utilidad» o sus iniciales. Esta obligación, como es lógico entender, no es de aplicación para invenciones de procedimiento. El propio artículo justifica la exclusión en razón de la particular naturaleza intangible de éstas.

La omisión del marcado no afecta la validez del título conferido. Sin embargo, el incumplimiento obliga, en caso de violación del derecho adquirido por la patente, a subsanar la omisión como requisito previo a la interposición de acciones civiles, penales o administrativas cuando ocurre infraccion o competencia desleal en perjuicio del titular ${ }^{109}$.

gable a cinco más. Esta solución se sustentó en la reducida presunción de validez del título, dada la ausencia de un examen de fondo de los requisitos de patentabilidad.

${ }^{109} \mathrm{El}$ marcado no es un requisito generalizado en la legislación comparada. Aparte de nuestra legislación, similar disposición aparece en las leyes de Japón, Taiwán y Corea. 
El artículo 72 de la ley no extiende al modelo de utilidad lo dispuesto en el capítulo quinto del título IV. Las licencias obligatorias no tienen justificación en monopolios de corta duración, tal como ya ha sido precisado. Como parte final del capítulo cuarto, el artículo 73 ordena que las tasas, en todos los casos, deben ser equivalentes a la mitad de las que correspondan a las patentes de invención. Los tipos de tasas son tres: tasa de presentación (artículo 38, inciso f), tasa de oposición (artículo 42, inciso f), y tasa de mantenimiento (artículo 61).

El mantenimiento de los derechos sobre patentes está sujeto al pago de tasas que generalmente son de periodicidad anual. Las características del modelo de utilidad justifican gravar en menor cuantía a sus titulares, en comparación con lo que se exige para las patentes de invención. Los costos de procesar una solicitud de modelo siempre son menores para la oficina administrativa. El procedimiento de concesión, por ser más corto y obviar mayormente el examen de fondo, reduce los gastos de la administración pública. Importa recalcar que el incremento de costos es un elemento disuasivo para las aplicaciones ${ }^{110}$.

\subsubsection{Capítulo V De la nulidad y la caducidad}

El artículo 74 de la ley extiende a los modelos de utilidad lo dispuesto en el capítulo sexto del título IV. La nulidad está regulada en el artículo 60, que establece la posibilidad de nulidad total o parcial en tres supuestos: obtención de la patente por persona distinta al inventor o cesionario; concesión obtenida sobre la base de información errada o manifiestamente deficiente que ha sido determinante para la concesión; y concesión contraventora de las normas sobre patentabilidad y sus requisitos. El precepto finaliza facultando la interposición de la acción, de oficio o a petición de parte, en cualquier momento durante la vigencia de la patente.

${ }^{110}$ En 1971 el Gobierno japonés decretó un aumento crítico en las tasas y costos de las aplicaciones y posteriores derechos. Inmediatamente operó una evidente declinación en el número de aplicaciones, al extremo que fue variada la proyección ascendente que hasta ese año se producía en relación al número de solicitudes.

Sobre el particular, ver SUZUYE, Takehiko, «Distinguishing Japan's utility model and patent law». Tabla I, pp. 223-225. 
La nulidad se funda en causas anteriores a la concesión del modelo cuando éstas presuponen un vicio de fondo que torna inválida la concesión y el efecto principal es la retroactividad; es decir, la nulidad se retrotrae a la fecha de concesion. El modelo de utilidad nulo, jurídicamente, implica que nunca existió. El primer supuesto contemplado es el hurto, que queda configurado cuando el contenido esencial de aquél —es decir, el invento protegido como modelo de utilidad - ha sido tomado de las descripciones de otro sin su consentimiento ${ }^{111}$. El segundo supuesto refiere a las descripciones que constan de defectos que no permiten visualizar claramente la invención -a fin de que la misma pueda ser ejecutada por un experto en la materia-, o si el objeto excede el contenido de la solicitud tal como fue presentada. El tercer supuesto ocurre cuando el invento no encuadra conceptualmente en lo que se entiende por modelo de utilidad o cuando se reivindica una creación contraria a la ley, o cuando se incumple con los requisitos positivos de patentabilidad (altura inventiva, novedad y aplicación industrial).

111 Resolución de la Corte Italiana de Apelaciones de Milán del 26 de octubre de 1951. En: Rivista di Diritto Industriale, parte II, 1953, p. 303. 